\title{
How electrodialysis configuration influences acid whey deacidification and membrane scaling
}

\author{
Guillaume Dufton, ${ }^{*}+$ Sergey Mikhaylin, ${ }^{\star} \dagger$ Sami Gaaloul, $\neq$ and Laurent Bazinet ${ }^{*} \dagger^{1}$ \\ *Institute of Nutrition and Functional Foods, Dairy Research Center, and Department of Food Sciences, Université Laval, Québec, QC, \\ Canada G1V 0A6 \\ †Laboratoire de Transformation Alimentaire et Procédés ÉlectroMembranaires (Laboratory of Food Processing and ElectroMembrane Processes), \\ Université Laval, Québec, QC, Canada G1V 0A6 \\ ‡Parmalat, Victoriaville, Québec, QC, Canada G6P 9V7
}

\section{ABSTRACT}

With the rising popularity of Greek-style yogurts in the past few years, the production of acid whey has drastically increased. If sweet whey is usually further processed, the acid whey valorization comes with challenges because its drying is jeopardized by its high mineral and organic acid contents. For this reason, prior demineralization and deacidification are usually performed at industrial scale using a combination of ion exchange resins and electrodialysis. This whole process represents large amounts of resources and energy consumption as well as an important production of effluents. The optimization of the electrodialysis technique, currently the focus of a few studies, could result in the replacement of the serial processes and would provide a cost-effective and eco-efficient alternative. In this work, the demineralization and deacidification of acid whey were compared via 2 electrodialysis configurations: one conventional and one using bipolar membranes. Both configurations allowed to reach interesting demineralization $(67 \%)$ and deacidification (44\%) rates. However, even though the appearance of fouling or scaling has never been reported, scalings of different natures were observed on membranes using both configurations. Amorphous calcium phosphate was identified on the anion exchange membranes for both configurations while calcite and brucite were identified on cation exchange ones using the bipolar membrane configuration. These scaling formations were linked to the migration of divalent ions and water splitting phenomenon caused by a high demineralization rate or by an already formed significant scaling.

Key words: acid whey, deacidification, demineralization, electrodialysis with bipolar membranes

Received February 23, 2018.

Accepted May 6, 2018

${ }^{1}$ Corresponding author: Laurent.Bazinet@fsaa.ulaval.ca

\section{INTRODUCTION}

Acid whey is the main co-product from the manufacturing of Greek yogurts, caseinate, and cream or cottage cheeses. It represents around $90 \%$ of the input milk volume and contains about $20 \%$ of its proteins and almost the entirety of its lactose (González Siso, 1996; Ryan and Walsh, 2016). The past few years have seen a tremendous increase in popularity for Greek-style yogurts, and with it, a constant increase in the volume of acid whey produced (Schultz and Parekh, 2011). In contrary to acid whey, sweet whey, produced during hard cheese production, for example, is usually further processed into whey powder, protein concentrate, and lactose by a drying step (Tsakali et al., 2010), typically realized by spray drying. If drying of sweet whey enables producers to obtain good quality powders, the acid whey drying results in a significantly sticky powder with major operational problems caused by the important amounts of calcium and lactic acid. It has been shown that the presence of said components had a main influence on the powder hygroscopic character and the decrease in lactose glass transition temperature (Saffari and Langrish, 2014; Chandrapala and Vasiljevic, 2017).

Therefore, one solution to allow acid whey processing at industrial scale is to demineralize and to remove lactic acid by combining ion exchange resins and electrodialysis (ED; Houldsworth, 1979; Williams and Kline, 1980; Hoppe and Higgins, 1992). The whole process represents a high investment, energy consumption, and the production of a large amount of effluents, during ion exchange resins regeneration, that needs to be treated. However, the ED step constitutes only one-fourth of the total energy consumption and effluent production (Greiter et al., 2002). The ED optimization for purposes of demineralization and lactic acid removal without the use of ion exchange resins could then provide a most cost-effective and eco-efficient alternative to the actual process. Hence, Chen et al. (2016) carried out laboratory-scale research to assess 
the feasibility of ED as part of the acid whey industrial treatment. They used a conventional ED stack consisting of anion (AEM) and cation exchange membranes (CEM) to treat different models and whey solutions. For a skimmed acid whey treated for $3 \mathrm{~h}$ at $45^{\circ} \mathrm{C}$, they obtained a similar energy consumption as for the sweet whey process $(\sim 0.014 \mathrm{kWh} / \mathrm{kg}$ of whey processed), with interesting lactic acid removal (a rate of $41 \%$ ) and demineralization (a rate of $\sim 57 \%$ ). They also found out that lactic acid removal was depending on the $\mathrm{pH}$, the temperature, and the amount of other ions present in the whey. Their highest lactic acid removal was obtained with a model solution $\left(99.7 \%\right.$ at $45{ }^{\circ} \mathrm{C}$ for a lactic acid + lactose $+\mathrm{NaCl}$ model solution) while they reached a maximum $74 \%$ deacidification rate for acid whey solutions using ultrafiltration permeate. However, the bipolar membrane, which was recently successfully used for the cranberry juice or wine deacidification, up to $80 \%$ of acid removal, has never been tested for acid whey deacidification (Calle et al., 2002; Serre et al., 2016).

Acid whey contains a significant amount of calcium involved in the drying issue (Saffari and Langrish, 2014; Chandrapala and Vasiljevic, 2017), and in combination with magnesium, these minerals have been identified, in many studies, as the major scaling agents during ED (Balster et al., 2005, 2007; Casademont et al., 2008; Mikhaylin and Bazinet, 2016). Furthermore, when the limiting current density is reached during an ED demineralization treatment due to a high demineralization rate, the water dissociation phenomenon appears. Water splitting leads to the dissociation of water into protons and hydroxyl ions influencing the formation of scaling such as brucite $\left(\mathrm{MgOH}_{2}\right)$ and calcite $\left(\mathrm{CaCO}_{3}\right.$; Casademont et al., 2010; Zeppenfeld, 2011; Mikhaylin et al., 2016). However, in the work of Chen et al. (2016) on acid whey deacidification, although they reached the limiting current density during their experiments in the presence of divalent ions (calcium and magnesium present in whey), they did not mention the occurrence or not of a scaling/fouling phenomenon on membranes. This aspect is nonetheless relevant as both the cleaning and replacement of membranes represent the major cost of the ED process (Xu, 2005; Strathmann, 2010).

In this context, the modification of the electrodialytic parameters and configuration could influence acid whey deacidification and demineralization with an effect on ionic species equilibrium and migration evolution. The objectives of the present work were to (1) compare 2 different ED configurations, one stacking only AEM and CEM (as used by Chen et al., 2016) and one stacking anion and cation exchange as well as bipolar membranes in terms of lactic acid deacidifica-
Table 1. Composition and physicochemical characteristics of the raw acid whey (Panesar et al., 2007; Saffari and Langrish, 2014; Chen et al., 2016; Bédas et al., 2017)

\begin{tabular}{lcc}
\hline Item & Acid whey $^{1}$ & $\begin{array}{c}\text { Values reported } \\
\text { in the literature }\end{array}$ \\
\hline TS $(\mathrm{g} / \mathrm{L})$ & $59.8 \pm 4.2$ & $50.0-70.0$ \\
Total protein $(\mathrm{g} / \mathrm{L})$ & $6.5 \pm 0.7$ & $4.2-10.0$ \\
Lactose $(\mathrm{g} / \mathrm{L})$ & $41.2 \pm 0.9$ & $38-49$ \\
Minerals $(\mathrm{g} / \mathrm{L})$ & $5.1 \pm 1.1$ & $4.7-7.0$ \\
$\mathrm{P}(\mathrm{g} / \mathrm{L})$ & $0.55 \pm 0.01$ & $0.44-0.90$ \\
$\mathrm{Ca}(\mathrm{g} / \mathrm{L})$ & $0.86 \pm 0.02$ & $0.43-1.60$ \\
$\mathrm{~K}(\mathrm{~g} / \mathrm{L})$ & $1.26 \pm 0.05$ & $1.28-1.82$ \\
$\mathrm{Mg}(\mathrm{g} / \mathrm{L})$ & $0.09 \pm 0.00$ & $0.09-0.19$ \\
$\mathrm{Na}(\mathrm{g} / \mathrm{L})$ & $0.39 \pm 0.03$ & $0.40-0.61$ \\
$\mathrm{Lactate}(\mathrm{g} / \mathrm{L})$ & $7.00 \pm 0.14$ & $5.18-8.00$ \\
Ratio lactate/lactose & 0.17 & $0.12-0.15$ \\
$\mathrm{pH}$ & 4.4 & $4.0-4.6$ \\
Conductivity $(\mathrm{mS} / \mathrm{cm})$ & $7.05 \pm 0.24$ & $8.27 \pm 0.42$ \\
\hline
\end{tabular}

${ }^{1}$ Values ( \pm SD) obtained by the average of at least 3 repeated measurements.

tion and demineralization; (2) study the influence of the configuration on scaling/fouling formation; and (3) identify the nature of the potential fouling/scaling in relation to the configuration used.

\section{MATERIALS AND METHODS}

\section{Whey}

The raw acid whey was obtained from a dairy processing plant owned by Parmalat-Canada (Victoriaville, Quebec, Canada). The acid whey samples were transported at $4^{\circ} \mathrm{C}$ from the plant and then stored at $-30^{\circ} \mathrm{C}$. Samples were thawed at $4^{\circ} \mathrm{C}$ before each experiment. The composition of the acid whey is described in Table 1 and was found to be consistent with that reported in the literature.

\section{Electrodialytic Configurations}

Electrodialysis experiments were performed using a MP type cell (ElectroCell AB, Täby, Sweden) with an effective surface area of $100 \mathrm{~cm}^{2}$. Two different ED configurations (CACAC and BACBAC) were tested as shown in Figure 1. Both were selected after preliminary testing of 8 different configurations (combination of membranes and solutions). For each, the anode was a dimensionally stable electrode $\left(\mathrm{DSA}-\mathrm{O}_{2}\right)$ and the cathode was a food-grade stainless-steel electrode. The potential difference was generated by a power supply (model HPD 30-10, Xantrex, Burnaby, BC, Canada). The solutions were circulated using centrifugal pumps and the flow rates controlled by flow-meters (Aalborg Instruments and Controls Inc., Orangeburg, SC). Both configurations consisted of 2 deacidification units. 


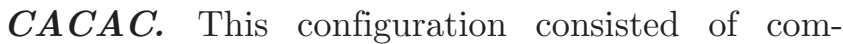
mercial food-grade CEM and AEM (Astom, Tokyo, Japan) with alternating diluate (acid whey compartment: AWComp) and concentrate (organic acid recovery compartment: OAComp) solutions (Figure 1a). This arrangement defined 3 closed loops containing a $20 \mathrm{~g} / \mathrm{L}$ of $\mathrm{Na}_{2} \mathrm{SO}_{4}$ electrolyte solution (volume of $2 \mathrm{~L}$, flow rate of $4 \mathrm{~L} / \mathrm{min}$ ), a $5.5 \mathrm{~g} / \mathrm{L}$ of $\mathrm{NaCl}$ aqueous concentrate solution $(2 \mathrm{~L}, 4 \mathrm{~L} / \mathrm{min})$, and acid whey $(2 \mathrm{~L}$, $4 \mathrm{~L} / \mathrm{min}$ ). Each closed loop was connected to a separate external tank, allowing a continuous recirculation. The third CEM was added to avoid the migration of anions, and more specifically lactate, in the electrode compartment. This configuration was the same as the one used by Chen et al. (2016) and reported to be effective for whey deacidification.

$\boldsymbol{B} \boldsymbol{A} \boldsymbol{C B} \boldsymbol{A} \boldsymbol{C}$. This configuration consisted in commercial food-grade CEM and AEM (Astom) as well as bipolar membranes (Astom; Figure 1b). Using this configuration, the addition of bipolar membranes allowed the lactic acid formation, following the migration of its anionic form (lactate) and its reaction with the $\mathrm{H}^{+}$ produced by the bipolar membranes in the OAComp. Another compartment was added to separate the bipolar membrane from the AWComp and to recover at the same time the mineral ions in whey (cation recovery compartment: CRComp). This arrangement defined 4 closed loops containing a $20 \mathrm{~g} / \mathrm{L}$ of $\mathrm{Na}_{2} \mathrm{SO}_{4}$ electrolyte solution (volume of $2 \mathrm{~L}$, flow rate of $4 \mathrm{~L} / \mathrm{min}$ ), a $5.5 \mathrm{~g} / \mathrm{L}$ of $\mathrm{KOH}$ aqueous concentrate solution $(2 \mathrm{~L}, 4 \mathrm{~L} /$ min), acid whey $(2 \mathrm{~L}, 4 \mathrm{~L} / \mathrm{min})$, and a $5.5 \mathrm{~g} / \mathrm{L} \mathrm{NaCl}$ cation recovery solution $(2 \mathrm{~L}, 4 \mathrm{~L} / \mathrm{min})$. Each closed loop was connected to a separate external tank, allowing a continuous recirculation. For the $5.5 \mathrm{~g} / \mathrm{L}$ of $\mathrm{KOH}$ concentrate solution, the $\mathrm{pH}$ was kept above 7 during the experiments by adding small volumes of $1 \mathrm{M} \mathrm{KOH}$. This compartment was kept at a basic $\mathrm{pH}$ to maintain lactic acid under its anionic form to ensure its migration through the anion exchange membranes.

\section{Protocol}

To apply the same migration driving force to both configurations, a constant current density of $100 \mathrm{~A} / \mathrm{m}^{2}$ was used. This current density was selected to be close to the initial current conditions reported by Chen et al. (2016) and below the initial limiting current density. At this current density, the voltage increased from 9 to $11 \mathrm{~V}$ to 38 to $50 \mathrm{~V}$ depending on the configuration. The tanks were kept at room temperature around $20^{\circ} \mathrm{C}$, and all the experiments were conducted for $3 \mathrm{~h}$. The composition of raw whey before and after ED was analyzed in terms of TS, protein, minerals, lactic acid, and lactose contents.

For all experiments, 3 replicates were performed. The electrical conductivity and $\mathrm{pH}$ values were recorded every $10 \mathrm{~min}$ for each solution as well as the voltage applied. Samples were taken in both OAComp and AWComp at $0,30,60,120$, and 180 min for organic acid concentration determination by HPLC. Membrane thickness and electrical conductivity were measured before and after each run and the membranes were dried and kept for mineral analyses and microscopic observation.
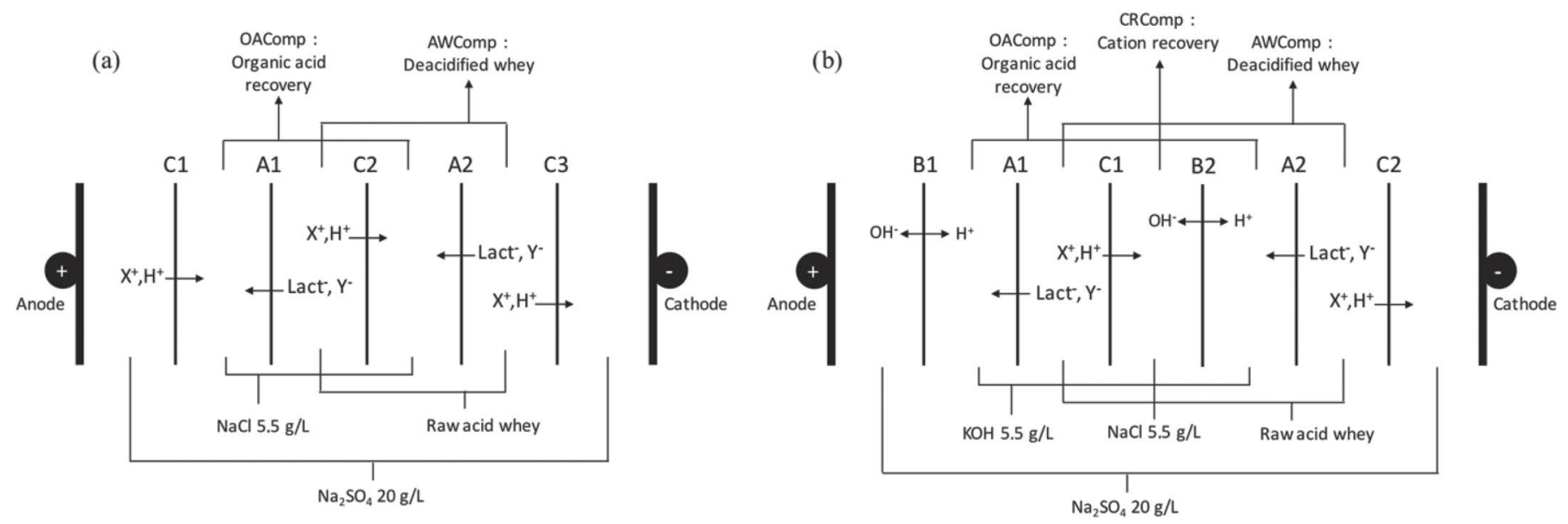

Figure 1. Electrodialysis (ED) configurations (a) CACAC and (b) BACBAC used for acid whey deacidification. C = cation exchange membrane, $\mathrm{A}=$ anion exchange membrane; $\mathrm{B}=$ bipolar membrane. $\mathrm{X}^{+}$and $\mathrm{Y}^{-}=$ionic species positively and negatively charged, respectively, present in the whey. OAComp = organic acid recovery compartment; AWComp = acid whey compartment; CRComp = cation recovery compartment; Lact. $=$ lactate. 


\section{Analyses}

Total Solids and Ash Contents. According to the AOAC method 945.46 (AOAC International, 2006), raw acid whey samples were weighed before drying for $1 \mathrm{~h}$ on a heating plate (Corning PC-420 Hot Plate Stirrer, Corning Inc., Corning, NY). The dried samples were then weighted again for TS content determination and further ashed in a furnace at $550^{\circ} \mathrm{C}$ overnight until they turned white. The samples were weighed after cooling and the ash content was determined as follows ( $m$ refers to the measured weights):

$$
\text { ash } \%=\frac{100 \cdot\left(m_{\text {crucible }+ \text { ashes }}-m_{\text {crucible }}\right)}{m_{\text {crucible }+ \text { sample }}-m_{\text {crucible }}} .
$$

Total Protein Content. Total protein content was determined by the measurement of the total nitrogen concentration. This was conducted according to the $\mathrm{Du}-$ mas combustion method using a TRUSPEC Leco FP528 (Leco, St. Joseph, MI) calibrated with EDTA. The raw acid whey was analyzed in triplicate before and after ED. A conversion factor of 6.38 was used to determine the protein content according to method ISO 14891:2002 (ISO, 2002).

Mineral Composition. Calcium, potassium, magnesium, sodium, and phosphorus concentrations were determined by optical emission spectrometry with inductively coupled plasma (ICP) as the atomization and excitation source (ICP-OES Agilent 5110 SVDV Agilent Technologies, Victoria, Australia), using the following wavelengths: $393.366,396.847$, and 422.673 (Ca); 766.491 (K); 279.553, 280.270, and 285.213 $(\mathrm{Mg}) ; 588.995$ and $589.592(\mathrm{Na})$; and 177.434, 178.222, 213.618, and $214.914(\mathrm{P})$. The analyses for all ions were carried out in axial or radial view (or both) directly on acid whey samples diluted 20 times. Ten-milliliter samples diluted 1:5 in distilled water were used for ion determination.

Organic Acid Contents. Organic acid concentrations were determined through HPLC using a chromatograph from Waters (Waters Corp., Milford, MA), equipped with a Hitachi (Foster City, CA) differential refractometer detector L-7490. An ICSep ICE-ION-300 column (Transgenomic, Omaha, NE) was used with $8.5 \mathrm{mM} \mathrm{H} \mathrm{H}_{2} \mathrm{SO}_{4}\left(180 \mu \mathrm{L}\right.$ of $\left.\mathrm{H}_{2} \mathrm{SO}_{4} / \mathrm{L}\right)$ as the mobile phase and at a flow rate of $0.4 \mathrm{~mL} / \mathrm{min}$. The column temperature was kept constant at $40^{\circ} \mathrm{C}$. Samples were centrifuged for $5 \mathrm{~min}$ at $5,311 \times g$ (Allegra 25R Centrifuge, Beckman Coulter, Brea, CA) and filtered (0.22 $\mu \mathrm{m}$ nylon; CHROMSPEC Syringe Filter, Ontario, Canada) before injection $(15 \mu \mathrm{L})$. A mixture of lactose anhydrous (PHR1025), citric acid (251275), DL-lactic acid (L1750), and acetic acid (338826, Sigma-Aldrich, St. Louis, MO) was used as an external standard to perform the quantification in milligrams per liter.

$\boldsymbol{p H}$. The $\mathrm{pH}$ of acid whey (AWComp), organic acid recovery (OAComp), and cation recovery (CRComp) solutions were measured using a pH meter model SP20 (VWR Symphony, Thermo Orion, West Chester, PA).

Conductivity. An YSI conductivity meter (model 3100, Yellow Springs Instrument, Yellow Springs, $\mathrm{OH}$ ) equipped with an immersion probe (model 3252, cell constant $\mathrm{K}=1 / \mathrm{cm}$ ) was used for measuring values in acid whey (AWComp), organic acid recovery (OAComp), and cation recovery (CRComp) solutions.

Global System Resistance. The global system resistance $(\mathrm{R}$, in $\Omega$ ) was calculated according to Ohm's law $(\mathrm{R}=\mathrm{U} / \mathrm{I})$. The voltage $(\mathrm{U}$, in $\mathrm{V})$ and current intensity (I, in A) values were directly obtained from the power supply.

Membrane Electrical Conductivity. Membrane conductance $\left(\mathrm{G}_{\mathrm{m}}\right)$ was measured using a conductivity clip (Laboratoire des Matériaux Échangeurs d'Ions, Créteil, France) with a $1 \mathrm{~cm}$ distance between the electrodes and the conductivity meter (model 35, Yellow Springs Instrument Co., Yellow Springs, OH). Membrane electrical resistance was calculated according to the model developed by Lteif et al. (1999) and Lebrun et al. (2003):

$$
\mathrm{R}_{\mathrm{m}}=\frac{1}{\mathrm{G}_{\mathrm{m}}}=\frac{1}{\mathrm{G}_{\mathrm{m}+\mathrm{s}}}-\frac{1}{\mathrm{G}_{\mathrm{s}}}=\mathrm{R}_{\mathrm{m}+\mathrm{s}}-\mathrm{R}_{\mathrm{s}},
$$

where $R_{m}$ is the transverse electric resistance of the membrane $(\Omega), \mathrm{G}_{\mathrm{m}}$ is the membrane conductance $(\mathrm{S})$, $\mathrm{G}_{\mathrm{m}+\mathrm{s}}$ is the conductance of the membrane and the solution measured together $(\mathrm{S}), \mathrm{G}_{\mathrm{s}}$ is the solution conductance $(\mathrm{S}), \mathrm{R}_{\mathrm{m}+\mathrm{s}}$ is the resistance of both membrane and solution measured together $(\Omega)$, and $\mathrm{R}_{\mathrm{s}}$ is the solution resistance $(\Omega)$. The membrane electrical conductivity was then calculated using the following relation (Lteif et al., 1999):

$$
\mathrm{K}=\frac{\mathrm{L}}{\mathrm{R}_{\mathrm{m}} \times \mathrm{A}},
$$

where $\mathrm{K}$ is the membrane conductivity $(\mathrm{mS} / \mathrm{cm}), \mathrm{L}$ is the membrane thickness $(\mathrm{cm}), \mathrm{R}_{\mathrm{m}}$ is the transversal resistance of the membrane $(\Omega)$, and $\mathrm{A}$ is the electrode surface $\left(1 \mathrm{~cm}^{2}\right)$.

Membrane Mineral Composition. The same elemental concentrations as for the liquid solutions were measured for the membranes by ICP-optical emission spectrometry as previously described. For both configurations, the analysis was conducted in triplicate 
on $18.75 \mathrm{~cm}^{2}$ pieces of AEM (CACAC, BACBAC; the bold character highlights the membrane analyzed) and CEM (CACAC, BACBAC). Pristine AEM and CEM were also analyzed as control. Membranes pieces of $18.75 \mathrm{~cm}^{2}$ were cut, weighted, and dried at $60^{\circ} \mathrm{C}$ overnight in an oven (VWR Gravity Convection Oven, Radnor, PA). The dried samples were then ashed in a furnace at $550^{\circ} \mathrm{C}$ overnight until they turned white. The samples were weighted after cooling and the ash content was determined according to Equation [1]. The ashes were resolubilized in $1 \mathrm{~mL}$ of $25 \%$ nitric acid and diluted in a 50-mL total volume with demineralized water (PURELAB Ultra, ELGA, High Wycombe, UK). The solutions were then filtered with membranes of $0.45-\mu \mathrm{m}$ pore size before the ICP analysis.

Scanning Electron Microscopy and Energy Dispersive Spectroscopy Analysis. The samples were first vacuum dried and then coated with a thin layer of gold to improve the image quality (Technics Hummer II Sputter Coater, Anatech Ltd., Battle Creek, MI). Images were then taken using a field emission gun scanning electron microscope with a magnification of $50 \times($ JMS840A SEM, JEOL, Peabody, MA). The microscope was equipped with a spectrometer using the energy dispersive spectroscopy (Bruker Analysis, Billerica, MA) at a $15-\mathrm{kV}$ accelerating voltage and a 15-mm working distance.

$\boldsymbol{X}$-Ray Diffraction. The analysis was performed using a D5000 Siemens diffractometer (Montreal, QC, Canada). The radiation source $(\mathrm{CuK} \alpha)$ was a copper lamp with a wavelength of $0.154 \mathrm{~nm}$. The $\mathrm{K} \alpha$ radiation of copper was generated at $30 \mathrm{~mA}$ and $40 \mathrm{kV}$. The scan rate of $0.02^{\circ} 2 \theta$ was applied to record patterns for $2 \theta$ ranging between $15^{\circ}$ and $65^{\circ}$. Results were analyzed using JADE software version 2.1 with JCPDS database from the International Centre for Diffraction Data (Newtown, PA), version 2001.

Statistical Analyses. Analyses of variance were performed on data and Tukey tests $(\alpha=0.05$ as probability level) were used to compare treatments (SAS software, version 6.3 for Windows, SAS Institute, Inc., Cary, NC).

\section{RESULTS AND DISCUSSION}

\section{Whey and Recovery Solutions Analysis}

Lactate Migration. Concerning lactate migration, it appeared that the configuration has no influence on the AWComp deacidification but affected the lactate recovery in the OAComp. Indeed, as shown in Figure 2, the lactate concentration decreased significantly $(P<$ 0.05) in the AWComp for both CACAC and BACBAC configurations from an average of $6.86 \pm 0.14 \mathrm{~g} / \mathrm{L}$ to $3.83 \pm 0.13 \mathrm{~g} / \mathrm{L}$ after $3 \mathrm{~h}$ of treatment, corresponding to a $44.1 \pm 1.9 \%$ deacidification rate. During the same time, in the OAComp, it increased to reach a final concentration of $2.83 \pm 0.35 \mathrm{~g} / \mathrm{L}$ using the CACAC configuration and $2.18 \pm 0.07 \mathrm{~g} / \mathrm{L}$ using the BACBAC configuration. This is equivalent to 41 and $31 \%$, respectively, of the lactate present in the initial whey. Furthermore, such a difference in lactate migration appeared after only $30 \mathrm{~min}$ of treatment and increased all along the deacidification process.

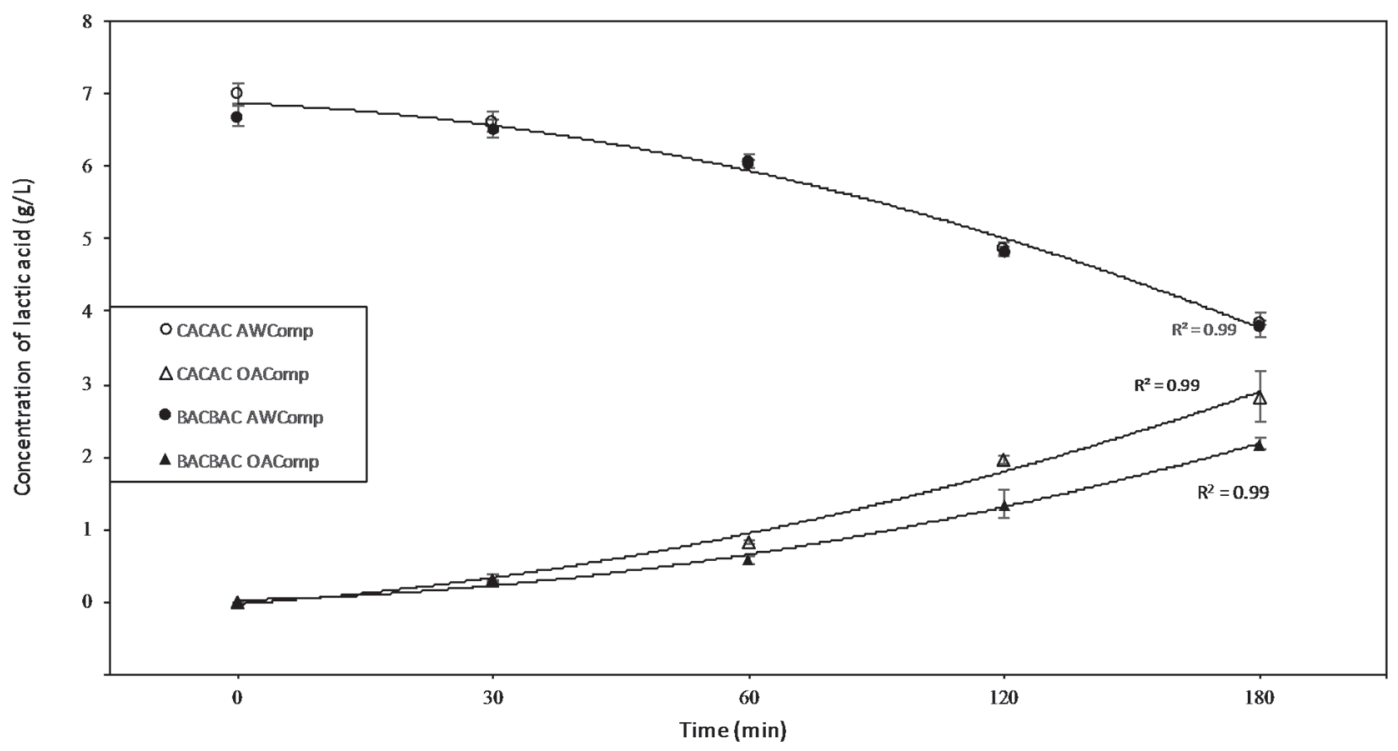

Figure 2. Evolution of lactic acid/lactate concentration in the acid whey compartment (AWComp) and organic acid recovery compartment (OAComp) for both CACAC and BACBAC configurations. All values are the average from 3 repetitions (error bar = SD). 
The initial lactic acid concentration in the acid whey was within the 6.5 to $7.0 \mathrm{~g} / \mathrm{L}$ range reported in the literature (Panesar et al., 2007; Saffari and Langrish, 2014; Chen et al., 2016). During these experiments, lactate was transferred from the AWComp to the OAComp solution through the anion exchange membranes present in both ED configurations. During the 3-h treatment, lactic acid concentration decreased in the whey for both CACAC and BACBAC configurations to reach a $44 \%$ similar deacidification rate, which was, for the same process duration, slightly higher than the $41 \%$ rate reported by Chen et al. (2016) for skimmed acid whey. Regarding the OAComp, the $41 \%$ recovery rate of the lactic acid initially present in the whey obtained for the CACAC configuration was in accordance with the depletion observed in the AWComp but wasn't reported by Chen et al. (2016). However, concerning the BACBAC configuration, only a $31 \%$ recovery rate was reached at the end. The increasing difference in lactic acid recovery rate between CACAC and BAC$\mathrm{BAC}$ configurations all along the treatment would be due to a potential trapping of lactate during its migration through the AEM membrane such as by lactate involvement in potential fouling or scaling phenomena.

Protein Content. The aim of the process was to remove the organic acids without altering or removing the proteins in the whey. The total protein content was then determined before and after ED to confirm that no protein was transferred during the process. The results are shown in Table 2 and allowed us to conclude that the whole protein content was preserved.

$\boldsymbol{p H}$. The results of the variance analysis showed that the whey $\mathrm{pH}$ (AWComp) was significantly influenced during the process by the ED configuration $(P$ $<0.0001$; Figure 3a). The $\mathrm{pH}$ slightly decreased from $4.4 \pm 0.1$ to $4.2 \pm 0.2(P<0.0001)$ for the CACAC configuration and passed from $4.4 \pm 0.2$ to $4.0 \pm 0.2(P$ $<0.0001$ ) for the BACBAC one. It also appeared that the $\mathrm{pH}$ evolution in whey, between both configurations, was only different in the last 40 to $50 \mathrm{~min}$. Concerning the OAComp, using the CACAC configuration, the $\mathrm{pH}$ decreased from $7.1 \pm 0.2$ to $5.8 \pm 0.2(P<0.05)$ in the first $80 \mathrm{~min}$ and increased afterward to reach $6.1 \pm$ $0.3(P<0.05)$. Regarding the BACBAC configuration, the $\mathrm{pH}$ in the OAComp remained stable (no significant difference, $P>0.05$ ) for the first $90 \mathrm{~min}$ from $12.0 \pm$ 0.6 to $10.8 \pm 1.1$ and then decreased to reach $7.5 \pm 0.4$ $(P<0.05 ;$ Figure $3 \mathrm{~b})$. Finally, concerning the CRComp present only in the BACBAC configuration and containing $\mathrm{NaCl}$, the $\mathrm{pH}$ increased rapidly during the first $40 \mathrm{~min}$ and thereafter was constant at an average of $11.9 \pm 0.1(P>0.05$; Figure $3 \mathrm{c})$.

Whatever the configuration, the $\mathrm{pH}$ decreased in the AWComp. This was mentioned by Chen et al. (2016),
Table 2. Total protein content before and after electrodialysis (ED)

\begin{tabular}{lc}
\hline Item $(\mathrm{g} / \mathrm{L} \pm \mathrm{SD})$ & $\begin{array}{c}\text { Result from Dumas } \\
\text { combustion method }\end{array}$ \\
\hline Whey before ED & $6.5 \pm 0.7^{\mathrm{a}}$ \\
Whey after ED (CACAC) & $6.2 \pm 0.4^{\mathrm{a}}$ \\
Whey after ED (BACBAC) & $6.5 \pm 0.5^{\mathrm{a}}$ \\
\hline
\end{tabular}

${ }^{\mathrm{a}}$ The same letter indicates no significant difference between the values $(P>0.05)$.

as an effect of lactic acid dissociation due to the migration of lactate ions and the possible occurrence of water splitting. The water splitting phenomenon would take place at the ion exchange membranes (AEM or CEM) diluate sides after reaching the limiting current density. This could be induced by fouling, scaling, a high demineralization rate, or a combination of these (Mikhaylin and Bazinet, 2016; Mikhaylin et al., 2016). It is well known that the rate of water dissociation is higher on AEM compared with CEM (Krol et al., 1999; Zabolotskii et al., 2012). Hence, in the AWComp, more protons will be produced via water splitting on AEM than hydroxyl ions produced on CEM. The difference observed between both configurations during the last 40 to $50 \mathrm{~min}$ of treatment would be due to the presence of a bipolar membrane, using the BACBAC configuration, generating protons all along that could leak through the AEM (Lorrain et al., 1996). Concerning the OAComp (Figure 3b), using the CACAC configuration, the $\mathrm{pH}$ decrease observed in the first $60 \mathrm{~min}$ would be due to the rapid migration of protons from the whey through the CEM. Afterward, the $\mathrm{pH}$ remained quite stable during the next $60 \mathrm{~min}$, possibly due to the migration of the anion form of phosphates, carbonates, and weak acids such as lactates, increasing the compartment buffer capacity. Then, after a 120-min process, it increased slightly again. This would be due to the occurrence of the previously mentioned water splitting phenomenon. For the BACBAC configuration, the $\mathrm{pH}$ of the OAComp solution remained quite stable until $90 \mathrm{~min}$ in the process (Figure $3 \mathrm{~b}$ ) because protons produced by the bipolar membrane were neutralized. These were reacting mainly with the hydroxide ions present in the basic solution and also the anionic organic acid forms and phosphates migrating through the AEM. After that time, the $\mathrm{pH}$ dropped due to the complete neutralization of $\mathrm{OH}^{-}$coming from the $\mathrm{KOH}$ solution. This would confirm the previous whey compartment acidification by $\mathrm{H}^{+}$leakage (Lorrain et al., 1996). After $130 \mathrm{~min}$, the $\mathrm{pH}$ stabilization was due to the addition of a $1 \mathrm{M}$ $\mathrm{KOH}$ solution to avoid further decrease until the end of the process. Finally, concerning the $\mathrm{pH}$ evolution in the CRComp using the BACBAC configuration (Figure $3 \mathrm{c}$ ), it increased logically and correlated with the 

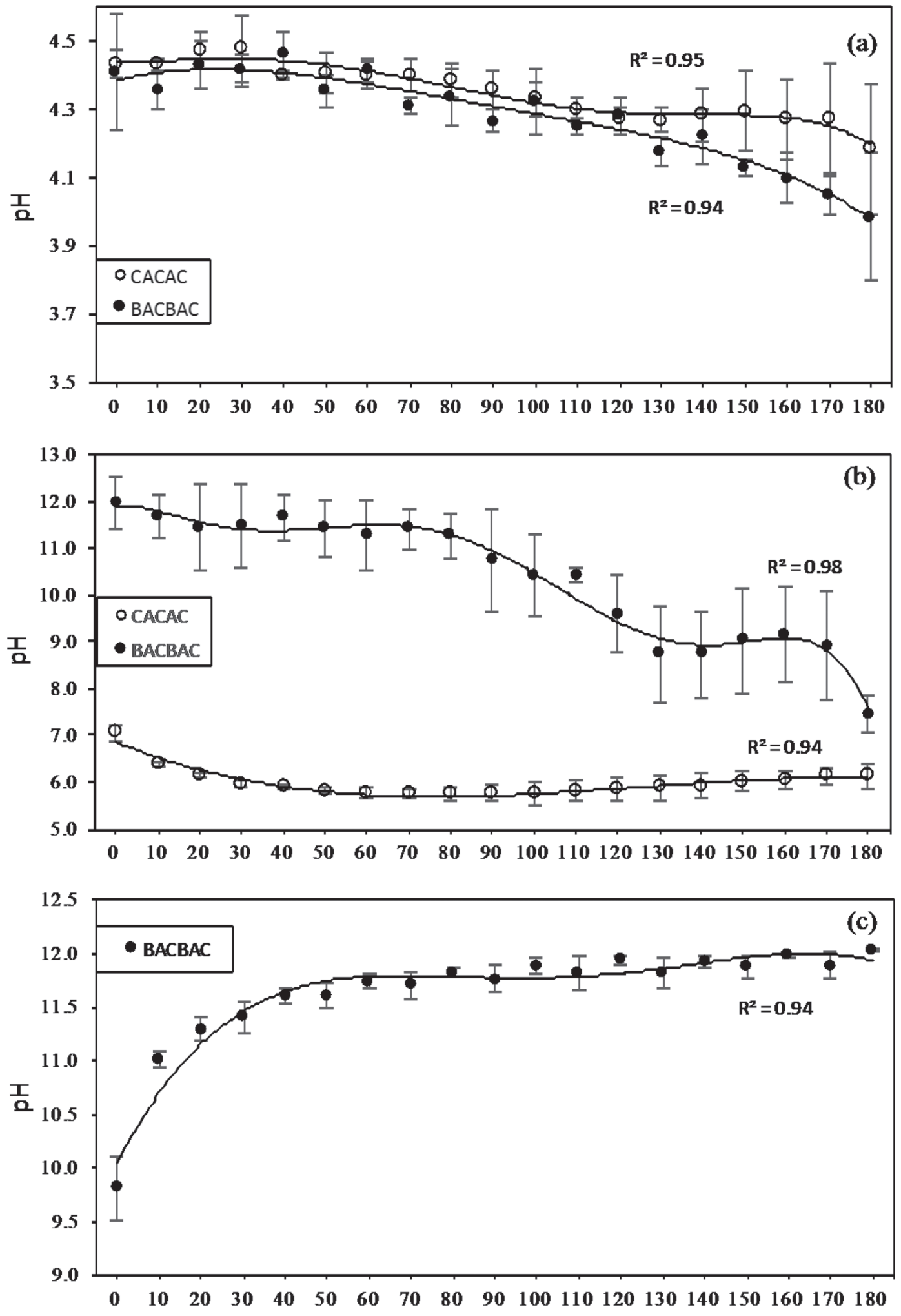

Time (min)

Figure 3. Evolution of $\mathrm{pH}$ in (a) the acid whey compartment and (b) the organic acid recovery compartment for both CACAC and BACBAC configurations and (c) cation recovery compartment for the BACBAC configuration only. All values are the average from 3 repetitions (error bar $=\mathrm{SD})$. 
production of hydroxide ions by the bipolar membrane during the first $40 \mathrm{~min}$ of process. After that time, the $\mathrm{pH}$ was quite constant potentially because hydroxide ions reacted with scaling agents or protons (or both) produced by water splitting on the CEM surface.

Conductivity. The conductivity evolution in the AWComp was similar for both configurations (Figure $4 \mathrm{a})$, decreasing from an average of $7.05 \pm 0.20 \mathrm{mS} / \mathrm{cm}$ to $2.31 \pm 0.04 \mathrm{mS} / \mathrm{cm}$ in $3 \mathrm{~h}(P<0.0001)$. Concerning the OAComp, using the CACAC configuration, the conductivity increased linearly from $7.37 \pm 0.24 \mathrm{mS} /$ cm to $12.85 \pm 0.47 \mathrm{mS} / \mathrm{cm}(P<0.0001$; Figure $4 \mathrm{~b})$. For the BACBAC configuration, it decreased from $16.11 \pm$ $0.38 \mathrm{mS} / \mathrm{cm}$ to $6.68 \pm 0.21 \mathrm{mS} / \mathrm{cm}(P<0.05)$ during the first $120 \mathrm{~min}$ and then increased again to reach a final value of $8.92 \pm 0.78 \mathrm{mS} / \mathrm{cm}(P<0.0001)$ in the last $60 \mathrm{~min}$ (Figure 4b). Finally, the conductivity of the CRComp solution using the BACBAC configuration increased linearly from $7.83 \pm 0.16 \mathrm{mS} / \mathrm{cm}$ to $14.09 \pm$ $0.22 \mathrm{mS} / \mathrm{cm}(P<0.0001$; Figure 4c)

The AWComp conductivity decrease for both configurations was mainly due to the demineralization of acid whey, by the migration of ions into the OAComp and CRComp. At the end of the process, the AWComp for both configurations reached a $67 \%$ demineralization rate, $10 \%$ higher than those reported by Chen et al. (2016) on skimmed acid whey for a 3-h process. Concerning the OAComp, the linear evolution of the conductivity using the CACAC configuration corresponded to a mineralization rate of $74 \%$ directly correlated with the acid whey demineralization. Regarding the BACBAC configuration, the OAComp solution conductivity decrease was explained by water formation from protons electrogenerated by the bipolar membrane and the hydroxide ions initially present as well as the formation of uncharged weak acids. The following increase was due to the addition of a $1 \mathrm{M} \mathrm{KOH}$ solution to maintain a basic $\mathrm{pH}$ and to enhance lactate migration. At last, the increase in conductivity of the CRComp solution for the BACBAC configuration was directly related to the demineralization observed in the AWComp.

\section{Electrodialytic Parameters}

Global System Resistance. The ED cell configuration had a significant influence on the system resistance evolution $(P<0.05)$. It increased significantly from $9.33 \pm 0.58 \Omega$ to $39.33 \pm 1.53 \Omega(P<0.05)$, corresponding to a 4 -fold increase, and from $10.50 \pm 0.71 \Omega$ to $49.00 \pm 1.41 \Omega(P<0.05)$, a 5 -fold increase, for the $\mathrm{CACAC}$ and the BACBAC configurations, respectively (Figure 5).

Furthermore, the significant increase in resistance, observed during the process, occurred at different times depending on the configuration. Indeed, the system resistance was stable for $130 \mathrm{~min}$ using the CACAC configuration and $110 \mathrm{~min}$ using the BACBAC before a significant increase appeared $(P<0.05)$. Using the CACAC configuration, this resistance increase can be correlated with the $\mathrm{pH}$ elevation appearing around that time in the OAComp. Regarding the BACBAC configuration, this increase can be correlated with the $\mathrm{pH}$ and conductivity changes in the OAComp, as well as with the divergence in the $\mathrm{pH}$ evolution in the AWComp between both CACAC and BACBAC. This resistance rising time is also correlated with the lactate migration divergence observed in the OAComp between both configurations. However, such an increase in global system resistance was not only the consequence of the sole whey compartment demineralization, but mainly of the membrane fouling or scaling, or both (Mikhaylin et al., 2014), following or leading to water splitting.

Membrane Photographs. At the end of each ED run, without any rinsing, the stack was dismantled and membrane photographs were taken for both configurations (Figure 6). Whatever the configuration, the membrane sides facing the diluate, in contact with the AWComp, were all free of fouling/scaling except the AEM from the BACBAC configuration where slight white traces were visible on the permeable structure (Figure 6). However, no conclusion on the nature of these traces (either fouling or scaling) could be made at this step. Regarding the CACAC configuration, a thick, plaster-like, crumbly, and easily removable by hand scaling was visible on the AEM in contact with the OAComp. As for the side facing the concentrate in contact with the CRComp, a CEM scaling was also observed for the BACBAC configuration (Figure 6). This scaling was thin but solid and strongly attached to the membrane.

The presence of fouling or scaling confirmed the $\mathrm{pH}$ variation observed previously as well as the global resistance evolution. However, it was surprising that no mention of scaling or fouling was reported in the Chen et al. (2016) study although they mentioned the appearance of water splitting. Furthermore, they did not discuss the influence of water splitting on potential fouling while working with skimmed acid whey containing divalent ions (Balster et al., 2007; Mikhaylin and Bazinet, 2016).

Membrane Thickness and Conductivity. The thickness and conductivity measurements gave a quick indication on the membranes integrity after the process. Indeed, as shown in Figure 7, although conductivity decreased after the process for all membranes, some of them were more affected than others. Hence, for the CACAC configuration, 2 of the 3 CEM were particularly affected (Figure 7a; C2, $P=0.07$ very 

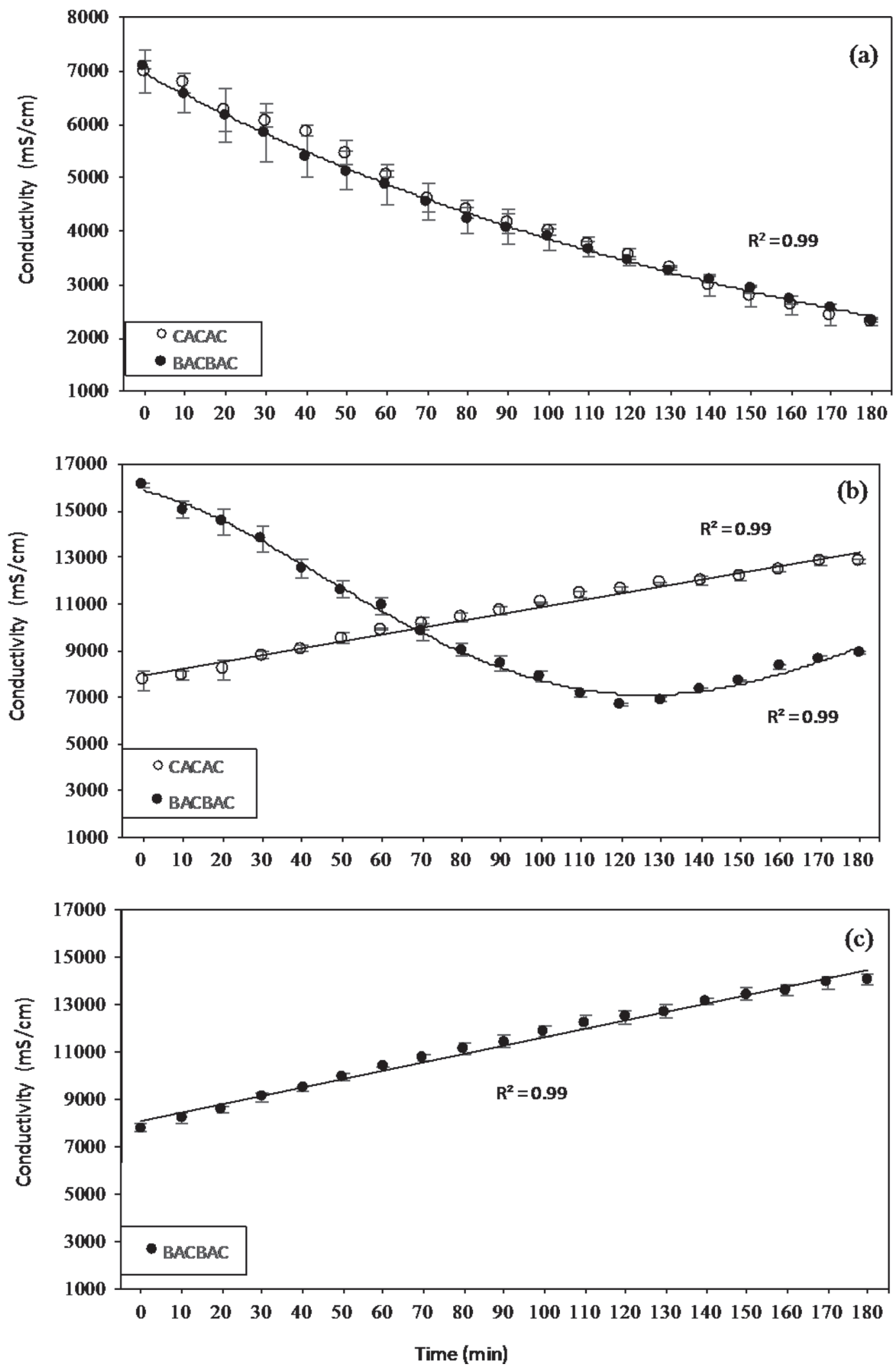

Figure 4. Evolution of conductivity in (a) the acid whey compartment and (b) the organic acid recovery compartment for both CACAC and BACBAC configurations and (c) cation recovery compartment for the BACBAC configuration only. All values are the average from 3 repetitions $($ error bar $=\mathrm{SD})$. 


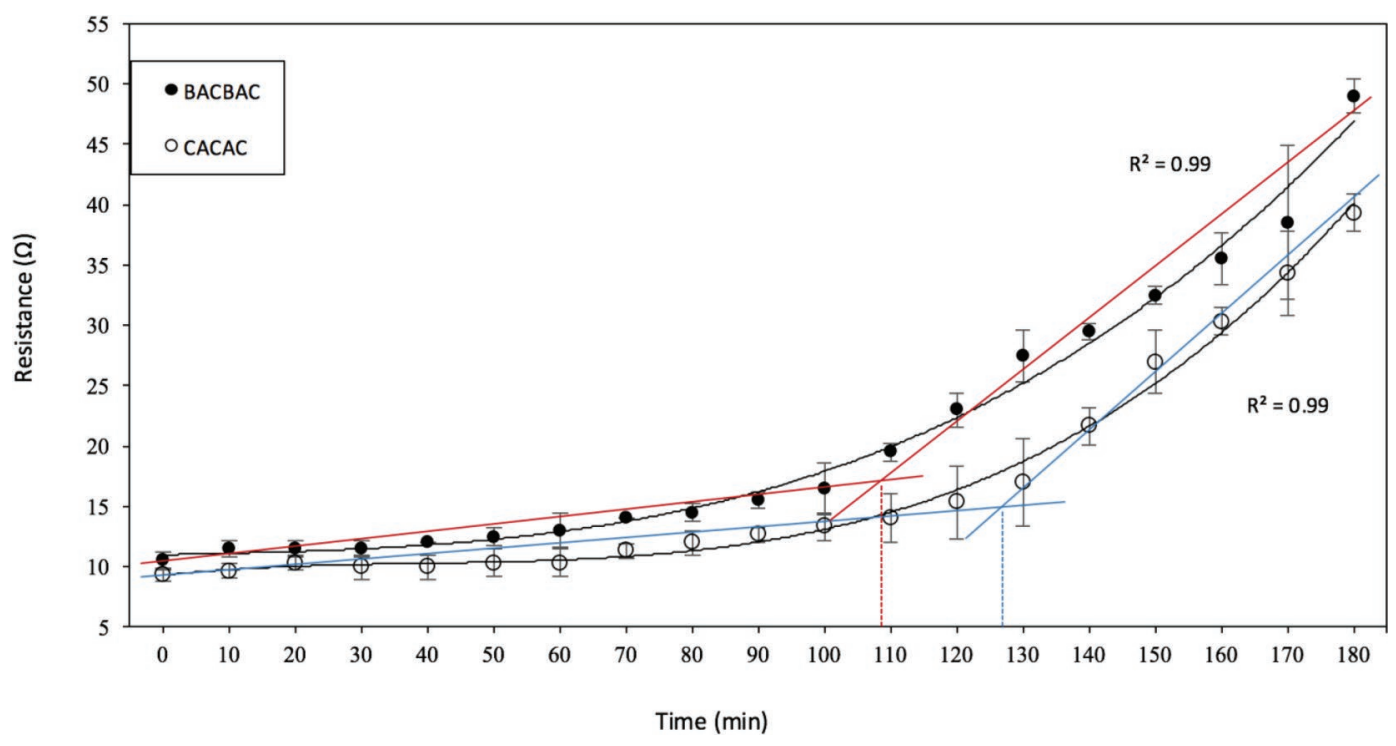

Figure 5. Global system resistance evolution during electrodialysis processes for both CACAC and BACBAC configurations. The intersection of the linear regressions for a curve represents the time at which the resistance of the system starts to increase due to fouling or scaling formation. All values are the average from 3 repetitions (error bar = SD). Color version available online.

close to the probability level acceptance of 0.05 and C3, $P<0.02$ ) with a loss in conductivity around $30 \%$. For the BACBAC configuration, CEM and AEM conductivity decreased significantly during the process $(P$ $<0.008$; Figure 7b), whereas no significant differences were observed on the bipolar membranes $(P>0.15)$. Furthermore, the CEM conductivity values were more affected than the AEM with respective decreases in conductivity of 92.9 versus $35.8 \%$.

These results confirmed the presence of the scalings observed previously and their influence on the mem- brane efficiency loss and global resistance evolution. The difference in scaling nature would explain the difference in membrane electrical conductivity losses observed using both configurations.

\section{Scaling Characterization}

Mineral Content. The mineral composition of all membranes was analyzed to determine the nature of the observed scalings (Table 3). Concerning the CACAC configuration, for the CEM, only the calcium presence

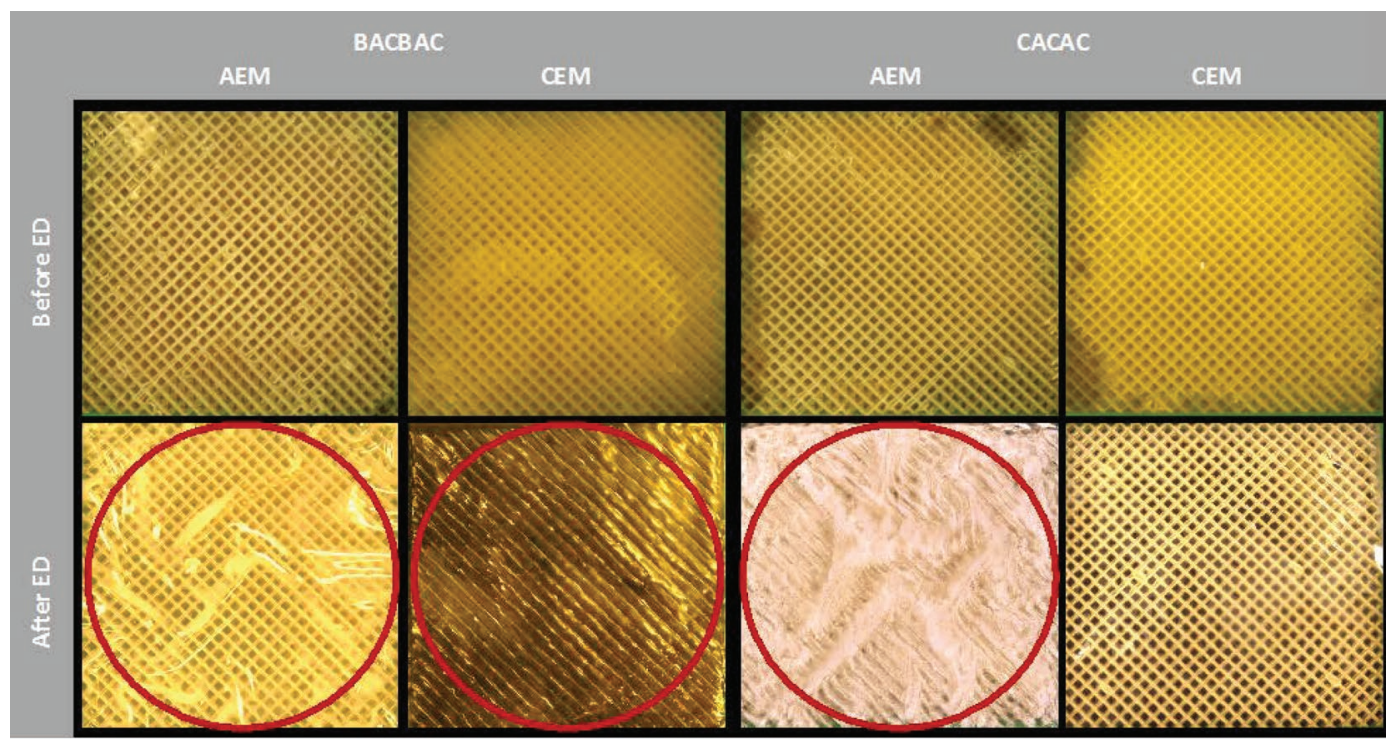

Figure 6. Photographs of the anode side of anion (AEM) and cation exchange membranes (CEM) before and after electrodialysis (ED) for both BACBAC and CACAC configurations. Color version available online. 
Table 3. Mineral composition of the cation exchange membranes (CEM) and anion exchange membranes (AEM) for both CACAC and BACBAC configurations

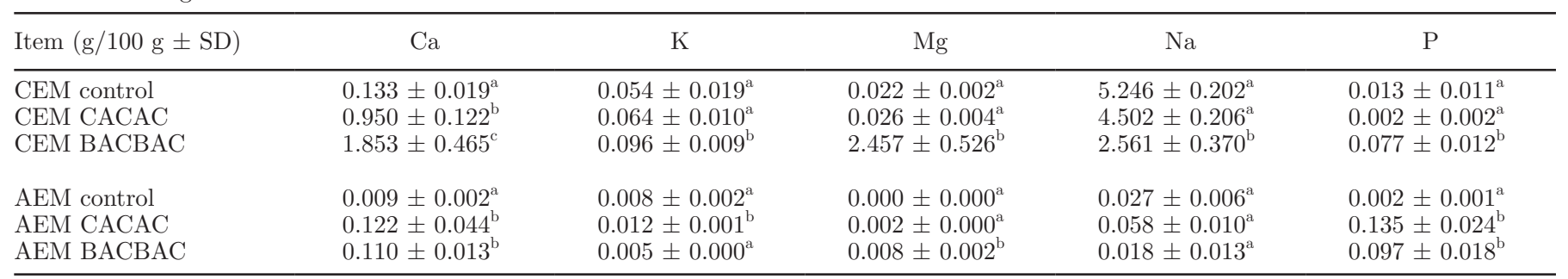

${ }^{\mathrm{a}-\mathrm{c}}$ The same letter in a column for 1 type of membrane indicates no significant difference between these values $(P>0.05)$.

was significantly different in comparison with a pristine one, with a concentration 7 times higher. For the AEM, the calcium and phosphorus concentrations were significantly higher in comparison with the control membrane both in similar proportions. Concerning the BACBAC configuration and the potential scaling mineral species, the treated CEM presented significant higher calcium (14 times), magnesium (100 times), and phosphorus (6 times) concentrations in comparison with the pristine membrane. At the same time, the AEM used in the BACBAC configuration demonstrated higher calcium and phosphorus concentrations, quite similar to those observed for the CACAC ones.

Consequently, regarding the CACAC configuration, the elemental analysis allowed us to assume the composition of the scaling observed on the AEM surfaces. It was mainly composed of calcium and phosphorus, indicating the possible presence of calcium phosphate, calcium hydrophosphate, calcium hydroxide, and other calcium-containing compounds. However, these precipitate formations need particular $\mathrm{pH}$ conditions and are more often triggered by an alkaline one (Destainville et al., 2003; Dorozhkin, 2010; Mikhaylin and Bazinet, 2016). As it was, the $\mathrm{pH}$ of the OAComp solution was never above 7 , the occurrence of water splitting, thus a local production of hydroxyl ions in the AEM vicinity, may have been responsible for this scaling. Concerning the CEM, a significant amount of calcium present could be due to scaling, yet invisible to the naked eye or simply to the late migration of this ion through the membranes. Indeed, calcium ions represent a substantial part of acid whey minerals and have relatively low electrophoretic mobility in addition to high scaling potential (Bazinet et al., 2000; Mikhaylin et al., 2016). Thus, its presence in the membrane or its precipitation on the membrane surface as well as inside the membrane nanochannels would explain the presence of calcium in the membrane at the end of the process, together with the conductivity decrease of the membranes shown in Figure 7 . For the BACBAC configuration regarding the AEM, around the same amount of calcium and phosphorus ions as for the CACAC one were found. However, the scaling was only visible on the AWComp side of the membranes. The calcium-induced scaling could not be due to water splitting on the surface of AEM as the ions generated on this side would have been protons, leading to local $\mathrm{pH}$ values away from the alkaline conditions needed. Potential water splitting might (a)

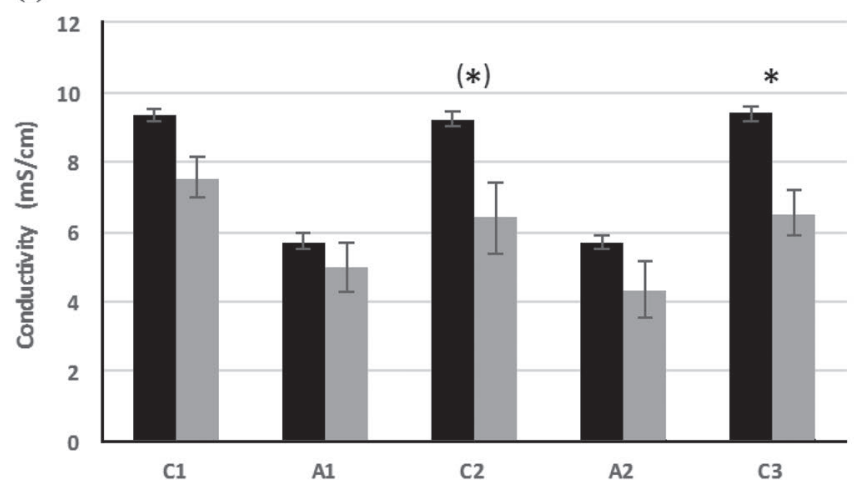

Before ED After ED

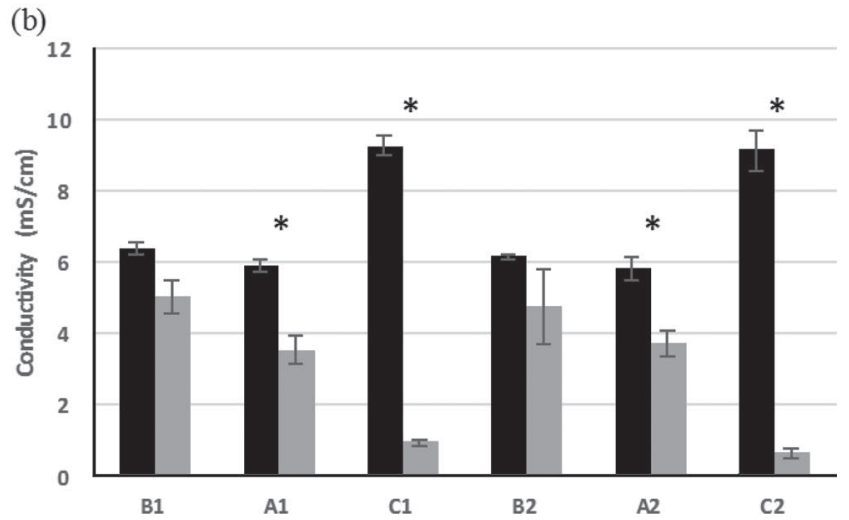

Figure 7. Membrane conductivity before and after electrodialysis (ED) for both (a) CACAC and (b) BACBAC configurations. * refers to a significant conductivity difference $(P<0.05)$ between before and after the ED process. $(*) P=0.07$. $\mathrm{C}=$ cation exchange membrane, A $=$ anion exchange membrane; $\mathrm{B}=$ bipolar membrane. All values are the average from 3 repetitions (error bar $=\mathrm{SD})$. 
have occurred on the CEM surface as well as leakage of hydroxyl ions generated on bipolar membranes could have created favorable conditions. Regarding the CEM, the very high amount of calcium and magnesium, in addition to the observed scaling and the great loss in conductivity, suggested that the scaling was most likely in the inner parts of the membranes. As for its exact nature, scanning electron microscopy and x-ray diffraction analyses have provided the missing information.

Scanning Electron Microscopy, Energy Dispersive Spectroscopy, and X-Ray Diffraction Analyses. The CEM from the CACAC configuration (Figure 8 ) showed the same visual as a pristine membrane (not shown) and the same response from the x-ray diffraction analysis with no detection of any crystalline form of scaling on the membrane surface (Figure 9). However, small amounts of calcium were detected by energy dispersive spectroscopy analysis on both AWComp and OAComp membrane sides and at similar abundance (Figure 10), confirming the previous mineral composition. On the contrary, the AEM were covered with deposits distributed on the membrane surface as shown in Figure 8. The x-ray diffraction did not reveal any crystalline form but the energy dispersive spectroscopy analysis, backing up the mineral composition results, indicated the presence of phosphorus and calcium in large quantities on both sides of the membranes (Figure 10). Concerning the BACBAC configuration, the CEM presented aggregates, identified by x-ray diffraction analysis as calcite (calcium carbonate) and brucite (magnesium hydroxide) on both sides. However, the energy dispersive spectroscopy analysis identified large quantities of magnesium, calcium, and oxygen ions on the CRComp side, the first one listed being the most abundant. On the AWComp side, lesser quantities were observed with calcium as the most abundant element. Regarding the AEM, they showed pristine-like OAComp sides but their AWComp opposites were covered by small aggregates similar to the ones observed using the CACAC configuration. Here again, the x-ray diffraction revealed no crystalline form whatever the side. However, the energy dispersive spectroscopy analysis displayed on the AWComp side large quantities of calcium and phosphorus.

Regarding the CACAC configuration, the analyses provided the confirmation that the CEM were free of scaling. The calcium found, following the mineral composition analysis, was then most likely the simple

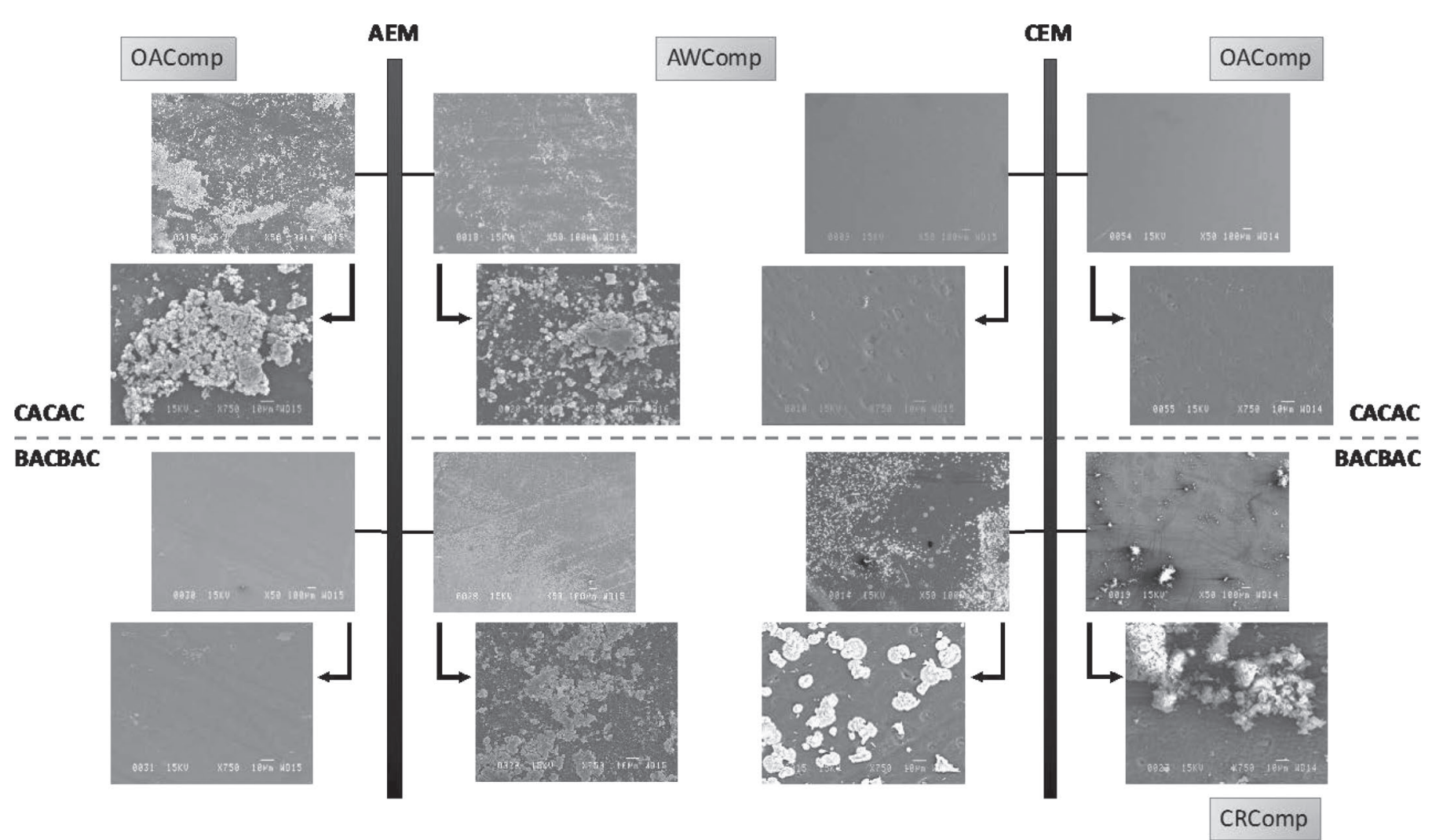

Figure 8. Scanning electron microscopy images of both sides of anion (AEM) and cation exchange membranes (CEM) for CACAC and BACBAC configurations with magnifications of $50 \times$ and $750 \times$. OAComp $=$ organic acid recovery compartment; AWComp $=$ acid whey compartment; CRComp = cation recovery compartment. 


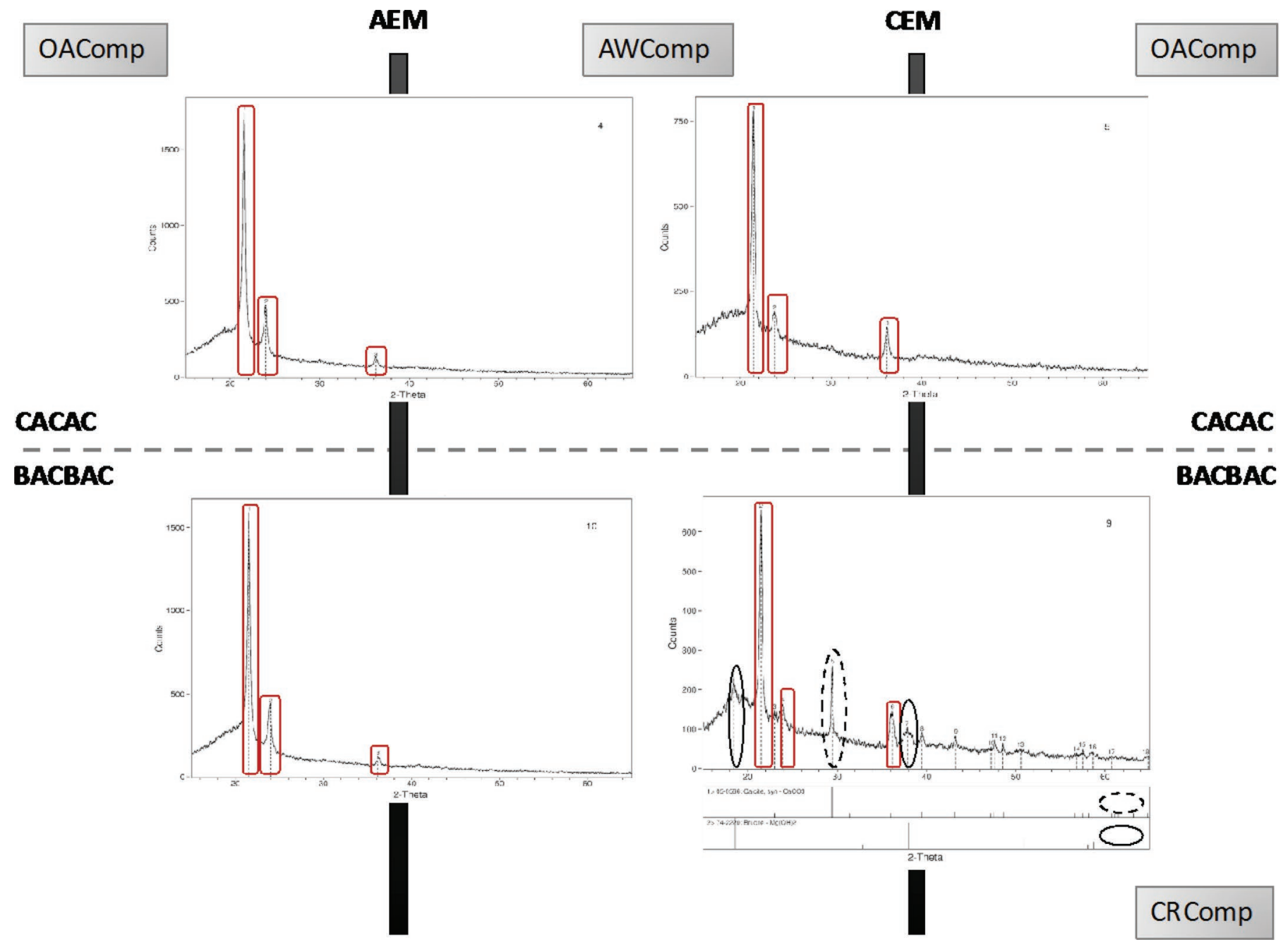

Figure 9. $\mathrm{x}$-Ray diffraction of anion (AEM) and cation exchange membranes (CEM) for CACAC and BACBAC configurations. Both sides of each membrane were analyzed and gave similar results. Rectangular outlined peaks are from the pristine membranes. Major peaks outlined with oval solid lines are for brucite crystals, and major peaks outlined with oval dotted lines are for calcite crystals. OAComp $=$ organic acid recovery compartment; AWComp = acid whey compartment; CRComp = cation recovery compartment. Color version available online.

remains of this ion's late migration through the membrane. As for the AEM, the absence of results from the x-ray diffraction analysis (Figure 9) indicated that calcium phosphate or hydrophosphate (or both) were under an amorphous form, narrowing consequently the possible precipitate forms. By comparing with literature observations (Destainville et al., 2003; Dorozhkin, $2010,2016)$, the proportion ratio of calcium/phosphorus, the $\mathrm{pH}$ stability conditions, and the microscopic observations tend to demonstrate that the scaling corresponded to an amorphous form of calcium phosphate (ACP: $\mathrm{Ca}_{\mathrm{x}} \mathrm{H}_{\mathrm{y}} \mathrm{PO}_{4 \mathrm{z}} \mathrm{nH}_{2} \mathrm{O}, \mathrm{n}=3-4.5 ; 15-20 \% \mathrm{H}_{2} \mathrm{O}$ ). Concerning the BACBAC configuration for CEM, their CRComp side surface was covered by brucite with some calcite blocks disseminated. These 2 scaling episodes involved reactions of magnesium (Equation [4]) and calcium in alkaline conditions as follows (Equations [5] and [6]; Casademont et al., 2010; Zeppenfeld, 2011):

$$
\begin{gathered}
\mathrm{Mg}^{2+}+2 \mathrm{OH}^{-} \rightarrow \mathrm{Mg}(\mathrm{OH})_{2} \\
\mathrm{HCO}_{3}^{-}+\mathrm{OH}^{-} \rightarrow \mathrm{CO}_{3}^{2-}+\mathrm{H}_{2} \mathrm{O} \\
\mathrm{Ca}^{2+}+\mathrm{CO}_{3}^{2-} \rightarrow \mathrm{CaCO}_{3} .
\end{gathered}
$$

Because the solubility constant of $\mathrm{Mg}(\mathrm{OH})_{2} \mathrm{Ks}=5$ $\times 10^{-12}(\mathrm{~mol} / \mathrm{L})$ is less than $\mathrm{CaCO}_{3}, \mathrm{Ks}=3.7 \times 10^{-9}$ (mol/L), the order of $\mathrm{Ca}$ and $\mathrm{Mg}$ compounds appearance in the various scaling sections was logical (Mikhaylin et al., 2014, 2016). In addition, the inhibition effect of magnesium and brucite on calcium composite formation 


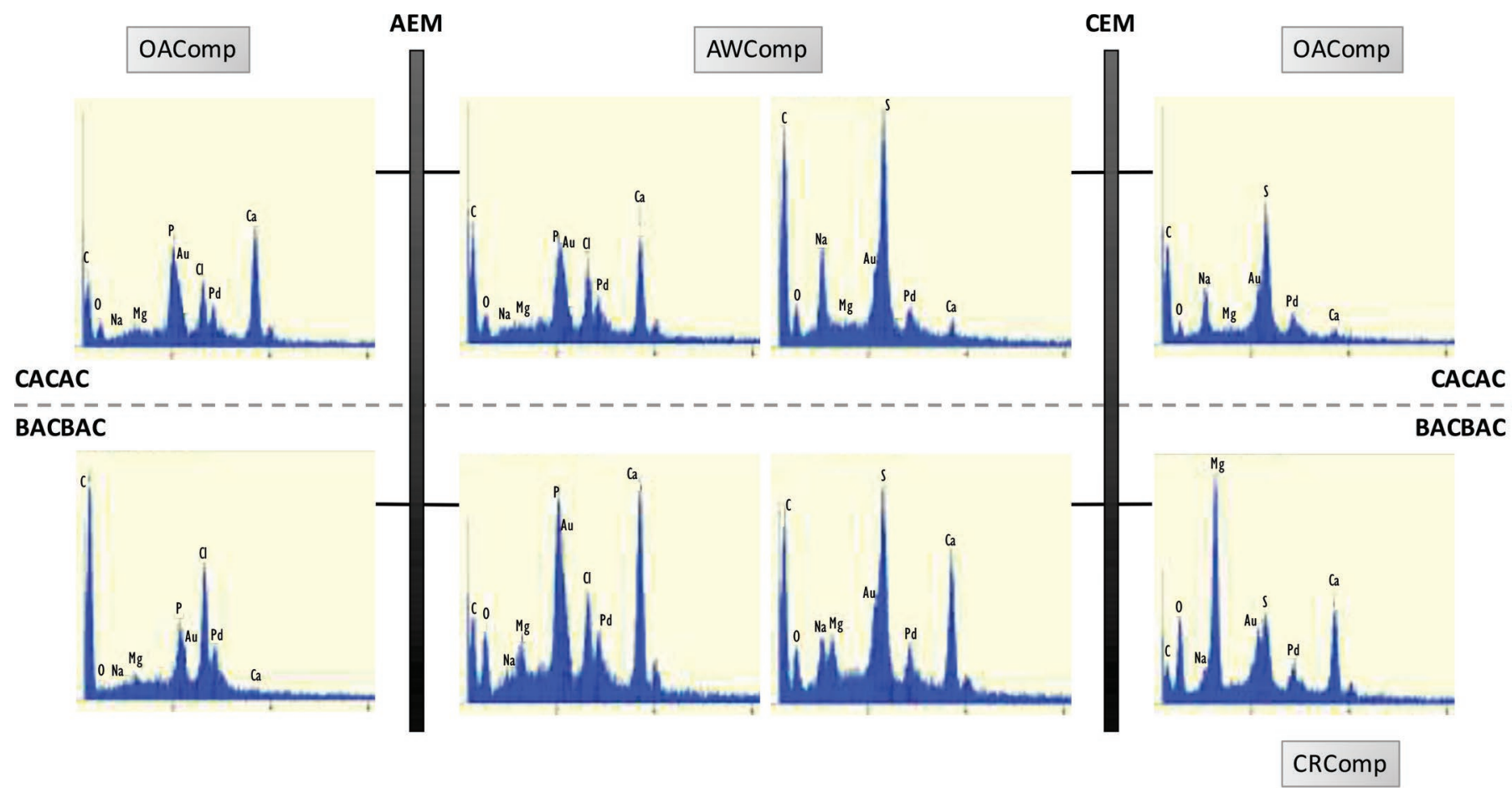

Figure 10. Energy dispersive x-ray spectroscopy of both sides of anion (AEM) and cation exchange membranes (CEM) for CACAC and BACBAC configurations. OAComp = organic acid recovery compartment; AWComp = acid whey compartment; CRComp = cation recovery compartment. Color version available online.

has already been studied (Zhang and Dawe, 2000; Chen et al., 2006; Mikhaylin et al., 2016) and can explain the predominance of the brucite mineral form over calcite. On the AWComp side of the membranes, the proportions were reversed and calcite was predominant over brucite. The calcium concentration in the whey was 10 times higher than the magnesium, even more during the process as the latter ion migrated faster, which can explain this difference. Moreover, as the scaling intensity was lower on this side, it probably occurred later during the process. Regarding the AEM, the analyses showed similar results as the CACAC ones, the scaling nature here being again ACP but on the AWComp side. The appearance of ACP in the whey would mean that the phosphate equilibrium was disturbed either by the CEM scaling or by water splitting on these membrane surfaces.

\section{General Discussion}

Two tentative models for CACAC (Figure 11) and BACBAC (Figure 12) configurations were proposed to explain the different evolutions in solution composition and electrodialytic parameters observed during the 3 -h deacidification treatment and that regarding the membrane scaling formations and their natures.
Concerning the CACAC configuration, during the first $60 \mathrm{~min}$ of the deacidification treatment, a stable $\mathrm{pH}$ value in the AWComp was observed whereas a drop occurred in the OAComp (from 7.0 to 5.8) due to the proton migration from the whey through the CEM. In parallel with the $\mathrm{H}^{+}$migration, $\mathrm{K}^{+}$would be the main cationic species migrating from whey during this period. An $80 \% \mathrm{~K}^{+}$demineralization rate was reached at the end of the process in comparison to $70 \%$ for sodium, $50 \%$ for calcium, and 30\% for magnesium. Furthermore, potassium was recognized as being the most mobile cation among calcium, magnesium, and sodium (Firdaous et al., 2007; Casademont et al., 2008) and the first to migrate (Bazinet et al., 2000; Mikhaylin et al., 2016). When the potassium concentration decreased, the migration of other cations became much more intensive as already demonstrated by Bazinet et al. (2000) during skim milk electroacidification and more recently by Mikhaylin et al. (2016). After that time and until $130 \mathrm{~min}$ of the process, the $\mathrm{pH}$ remained quite stable due to the increasing buffering capacity of the OAComp solution caused by a lactate delayed migration into this compartment. The electrophoretic mobility of $\mathrm{Cl}^{-}(7.91$ $\left.\times 10^{-8} \mathrm{~m}^{2} / \mathrm{s} \cdot \mathrm{V}\right)$ was greater than that of lactate $(<4.23$ $\times 10^{-8} \mathrm{~m}^{2} / \mathrm{s} \cdot \mathrm{V}$; Bazinet and Castaigne, 2011). The lactate migration from the AWComp to the OAComp 
lactate dissociation)
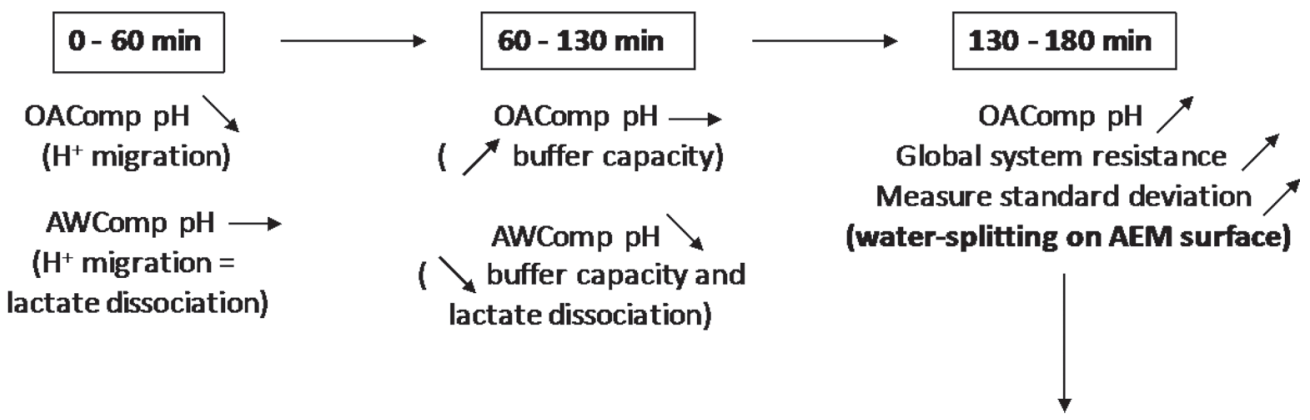

OAComp :
OWComp :

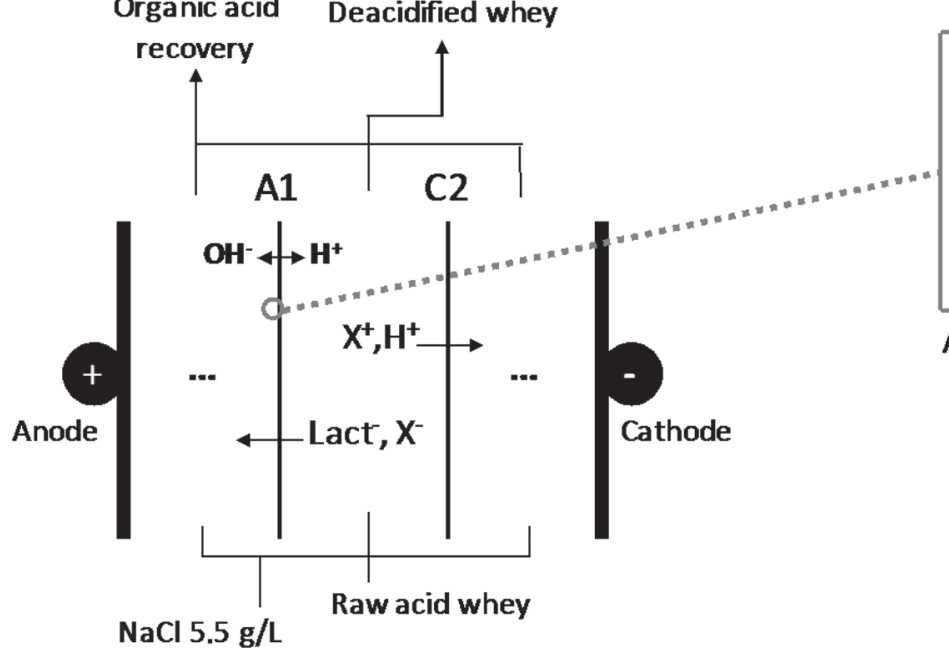

AEM scaling

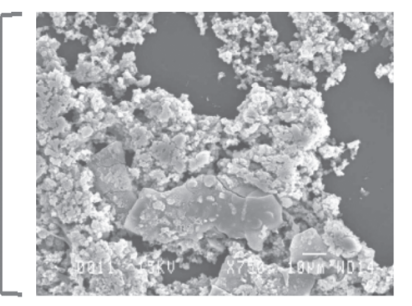

Amorphous calcium phosphate

Figure 11. $\mathrm{pH}$ evolution and reactions occurring during a 3-h electrodialysis of acid whey using the CACAC configuration. AEM $=$ anion exchange membranes; $\mathrm{C}=$ cation exchange membrane, $\mathrm{A}=$ anion exchange membrane; $\mathrm{X}^{+}$and $\mathrm{X}^{-}=$ionic species positively and negatively charged; Lact $=$ lactate. OAComp $=$ organic acid recovery compartment; AWComp $=$ acid whey compartment.

induced further release of protons in the whey due to the lactate/lactic acid $(\mathrm{pKa}=3.86)$ equilibrium shift. At the whey $\mathrm{pH}$ (4.6), $80 \%$ of the lactic acid was under its dissociated form. Consequently, by depleting lactate from the whey, lactic acid will further dissociate hence releasing protons (Equation [7]).

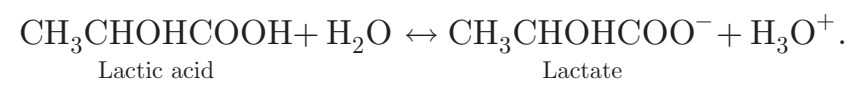

In addition to the lowered buffering capacity of the whey, the production of $\mathrm{H}^{+}$from the lactic acid dissociation can explain the slight $\mathrm{pH}$ decrease in the AWComp. The conductivity lowering was still linear during this second period since the migration of $\mathrm{K}^{+}$ was then compensated by other cations such as divalent ones which started to migrate more intensively. Due to this demineralization of the whey, a water splitting phenomenon also appeared on the AEM membrane surfaces during the same time and more likely in the last third (global demineralization rate of $46 \%$ ). Hence, after 130 min of the process, the $\mathrm{pH}$ of the OAComp solution rose a little while the system resistance increased drastically. Higher standard deviations on $\mathrm{pH}$ measurements in all compartments were also observed during this last third period. At the end of the process, when the cell was dismantled, large amounts of amorphous calcium phosphate were visible on the AEM. The occurrence of water splitting, during the second period, on the AEM surface favored the scaling formation on the OAComp side by the reaction of $\mathrm{OH}^{-}$with calcium and phosphate present in the compartment and migrating from the AWComp. With hydroxyl ions produced in the OAComp and protons in the AWComp, the local $\mathrm{pH}$ in the vicinity of the membrane greatly increased on one side while decreasing on the other, creating favorable conditions for the formation of an amorphous calcium phosphate (Destainville et al., 2003; Dorozhkin, 2010) (Equations [8] and [9]). 


$$
\begin{gathered}
\mathrm{HPO}_{4}^{2-}+\mathrm{OH}^{-} \leftrightarrow \mathrm{PO}_{4}^{3-}+\mathrm{H}_{2} \mathrm{O}, \\
9 \mathrm{Ca}^{2+}+6 \mathrm{PO}_{4}^{3-} \rightarrow \mathrm{Ca}_{9}\left(\mathrm{PO}_{4}\right)_{6} \mathrm{nH}_{2} \mathrm{O} .
\end{gathered}
$$

When this scaling has covered a certain surface of the membrane at the end of the second period, the global resistance of the system started to drastically increase, consequently enhancing water dissociation and further scaling formation.

Regarding the BACBAC configuration, the first $40 \mathrm{~min}$ of the process were similar to the previous configuration for the AWComp with a decrease in the $\mathrm{pH}$ of 0.41 unit whereas a stable value was observed in the OAComp solution. However, in the CRComp, the $\mathrm{pH}$ increased as expected due to the production of $\mathrm{OH}^{-}$by the bipolar membrane. Concerning $\mathrm{K}^{+}$, an $80 \%$ demineralization rate was reached at the end of the process in the AWComp while reaching $70 \%$ for sodium, $50 \%$ for calcium, and $30 \%$ for magnesium, similar values were obtained using the CACAC configuration. The first sig- nificant change appeared after $40 \mathrm{~min}$ in the CRComp when the $\mathrm{pH}$ became stable, whereas it should have logically continued to increase with $\mathrm{OH}^{-}$constantly generated by the bipolar membranes. This $\mathrm{pH}$ stabilization would be due to the fact that hydroxide ions, produced or present (or both) in the solution, participated in a scaling reaction. Indeed, as explained previously, the migration of both $\mathrm{Ca}^{2+}$ and $\mathrm{Mg}^{2+}$ was delayed by that of $\mathrm{K}^{+}$and $\mathrm{H}^{+}$, and these divalent ions then probably started to migrate in a significant amount after around $40 \mathrm{~min}$ of the process. The rapid formation of calcite and brucite on the CEM surface facing the CRComp was due to the high solution alkalinity in this compartment. This multilayered scaling on the CRComp side of CEM was already reported in previous studies by Casademont et al. (2010). Once started, these scalings, by expanding on the membrane surface between 40 and 110 min, led to water splitting (Mikhaylin et al., 2014). Moreover, these scalings led to the decrease of CEM permselectivity and $\mathrm{OH}^{-}$leakage toward the AWComp (Mikhaylin et al., 2014, 2016). Water dissociation and

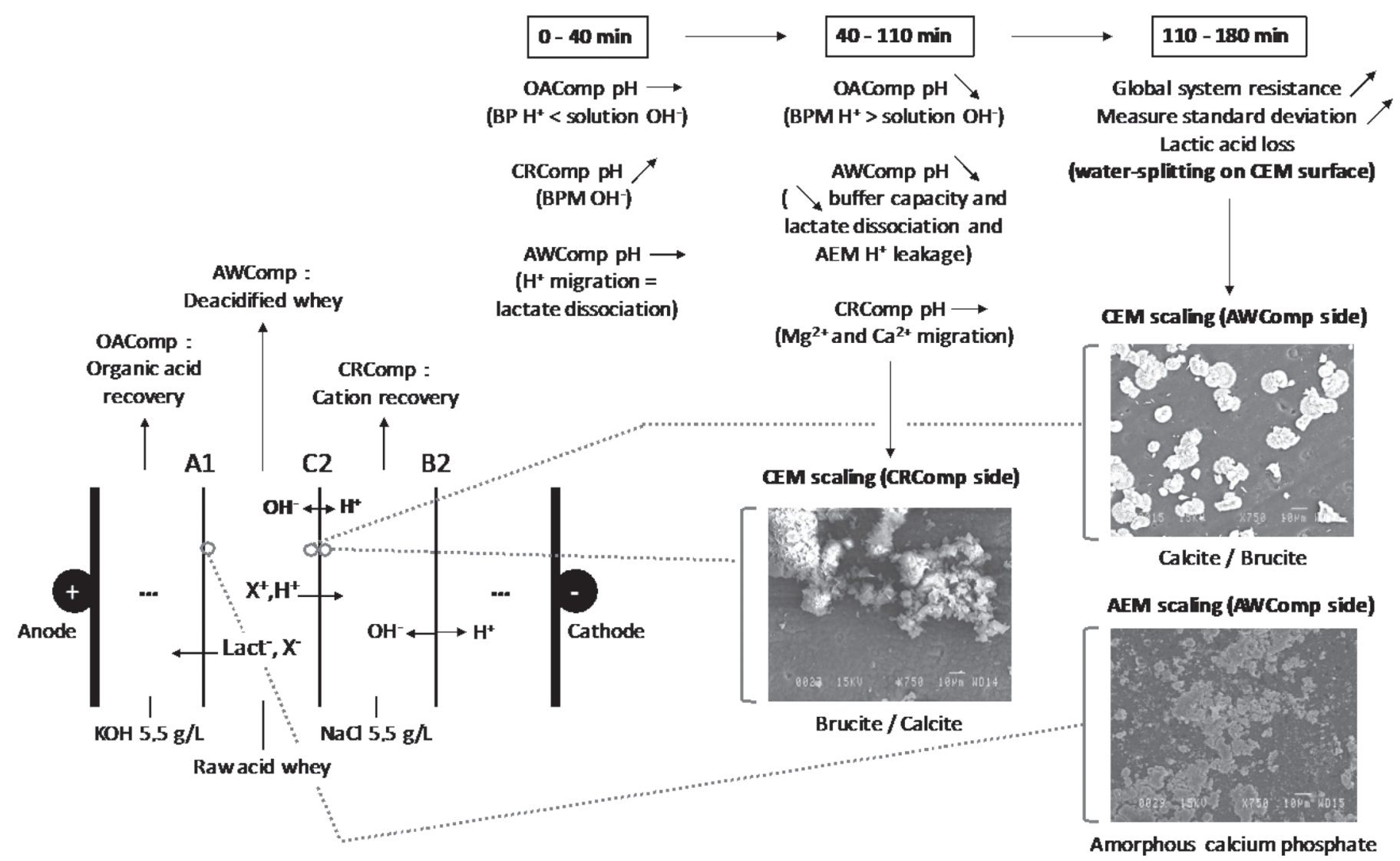

Figure 12. $\mathrm{pH}$ evolution and reactions occurring during a 3-h electrodialysis of acid whey using the BACBAC configuration. OAComp $=$ organic acid recovery compartment; $\mathrm{AWComp}=$ acid whey compartment; CRComp $=$ cation recovery compartment; Lact- $=$ lactate; $\mathrm{BPM}=$ bipolar membranes; AEM (or A) = anion exchange membrane; CEM (or C) = cation exchange membrane; $\mathrm{X}^{+}$and $\mathrm{X}^{-}=$ionic species positively and negatively charged. 
$\mathrm{OH}^{-}$leakage following the CEM scaling led to further deposition of calcium and magnesium compounds on the AWComp side of the CEM. At the same time, these electrogenerated and leaked $\mathrm{OH}^{-}$ions modified the chemical equilibrium of the phosphates present in the whey (Equation [8]). This led to an amorphous calcium phosphate formation on the AEM surface facing the AWComp. After 110 min of the process, well-developed water splitting and membrane scaling were responsible for the drastic increase in electrical resistance observed. Furthermore, by locally disturbing the chemical equilibrium of the whey, these phenomena probably led to the precipitation, trapping, or both of lactate during scaling, explaining its recovery difference observed at the end of the process.

\section{CONCLUSIONS}

It appeared from these results that both ED configurations allowed similar demineralization $(67 \%)$ and lactic acid deacidification (44\%) rates. However, the various nature of scalings on different membrane sides was observed after the deacidification treatment in relation to the configuration. Such scaling would have detrimental repercussions on the industrial application of the process by the drastic increase in energy consumption and also membrane cleaning/replacement. However, this study allowed us to identify for the first time the minerals involved in the process, as well as the nature of these scaling episodes in addition to the phenomena responsible for such formations.

\section{ACKNOWLEDGMENTS}

The Natural Sciences and Engineering Research Council of Canada (NSERC) financial support is acknowledged. This work was supported by the NSERC Industrial Research Chair on ElectroMembrane processes aiming the ecoefficiency improvement of biofood production lines (grant IRCPJ 492889-15 to Laurent Bazinet) and the NSERC Discovery Grants Program (grant SD RGPIN-2018-04128 to Laurent Bazinet). The authors thank Jacinthe Thibodeau and Diane Gagnon, research professionals at Université Laval, for their involvement in this project. Also, the authors thank André Ferland (Laval University) and Jean Frenette (Laval University) for their assistance in scanning electron microscopy and x-ray diffraction analyses and Alain Brousseau (Laval University) as well as Véronique Richard (Laval University and INAF) for their respective involvement in ICP and HPLC ones. The authors thank Dominique Fournier (DF Linguistic Services) for revising the manuscript.

\section{REFERENCES}

AOAC International. 2006. Official methods of analysis Proximate Analysis and Calculations Ash Determination (Ash) Milk - item 53. Method 945.46. 17th ed. AOAC International, Gaithersburg, MD.

Balster, J., O. Krupenko, I. Pünt, D. F. Stamatialis, and M. Wessling. 2005. Preparation and characterisation of monovalent ion selective cation exchange membranes based on sulphonated poly(ether ether ketone). J. Membr. Sci. 263:137-145. https://doi.org/10 .1016/j.memsci.2005.04.019.

Balster, J., I. Pünt, D. F. Stamatialis, H. Lammers, A. B. Verver, and M. Wessling. 2007. Electrochemical acidification of milk by whey desalination. J. Membr. Sci. 303:213-220. https://doi.org/10 .1016/j.memsci.2007.07.015.

Bazinet, L., and F. Castaigne. 2011. Concepts de génie alimentaire: Procédés associés et applications à la conservation des aliments. Tec \& Doc, Lavoisier Quebec, QC, Canada.

Bazinet, L., F. Lamarche, D. Ippersiel, B. Mahdavi, and J. Amiot. 2000. Effect of cationic membrane permselectivity on the efficiency of skim milk electroacidification. J. Agric. Food Chem. 48:25952601. https://doi.org/10.1021/jf990791s.

Bédas, M., G. Tanguy, A. Dolivet, S. Méjean, F. Gaucheron, G. Garric, G. Senard, R. Jeantet, and P. Schuck. 2017. Nanofiltration of lactic acid whey prior to spray drying: Scaling up to a semiindustrial scale. Lebensm. Wiss. Technol. 79:355-360. https://doi .org/10.1016/j.lwt.2017.01.061.

Calle, E. V., J. Ruales, M. Dornierb, J. Sandeauxc, R. Sandeauxc, and G. Pourcelly. 2002. Deacidification of the clarified passion fruit juice. Desalination 149:357-361.

Casademont, C., M. A. Farias, G. Pourcelly, and L. Bazinet. 2008. Impact of electrodialytic parameters on cation migration kinetics and fouling nature of ion-exchange membranes during treatment of solutions with different magnesium/calcium ratios. J. Membr. Sci. 325:570-579. https://doi.org/10.1016/j.memsci.2008.08.023.

Casademont, C., G. Pourcelly, and L. Bazinet. 2010. Bilayered selforiented membrane fouling and impact of magnesium on $\mathrm{CaCO} 3$ formation during consecutive electrodialysis treatments. Langmuir 26:854-859. https://doi.org/10.1021/la902284k.

Chandrapala, J., and T. Vasiljevic. 2017. Properties of spray dried lactose powders influenced by presence of lactic acid and calcium. J. Food Eng. 198:63-71. https://doi.org/10.1016/j.jfoodeng.2016 .11.017.

Chen, G. Q., F. I. I. Eschbach, M. Weeks, S. L. Gras, and S. E. Kentish. 2016. Removal of lactic acid from acid whey using electrodialysis. Separ. Purif. Tech. 158:230-237. https://doi.org/10.1016/j .seppur.2015.12.016.

Chen, T., A. Neville, and M. Yuan. 2006. Influence of $\mathrm{Mg} 2+$ on $\mathrm{CaCO}_{3}$ formation-bulk precipitation and surface deposition. Chem. Eng. Sci. 61:5318-5327. https://doi.org/10.1016/j.ces.2006.04.007.

Destainville, A., E. Champion, and E. Laborde. 2003. Synthesis, characterization and thermal behavior of apatitic tricalcium phosphate. Mater. Chem. Phys. 80:269-277.

Dorozhkin, S. V. 2010. Amorphous calcium (ortho)phosphates. Acta Biomater. 6:4457-4475. https://doi.org/10.1016/j.actbio.2010.06 .031 .

Dorozhkin, S. V. 2016. Biphasic, triphasic, and multiphasic calcium orthophosphates. Acta Biomater. 8:33-95. https://doi.org/10 $.1002 / 9781119242598 . c h 2$.

Firdaous, L., J. P. Malériat, J. P. Schlumpf, and F. Quéméneur. 2007. Transfer of monovalent and divalent cations in salt solutions by electrodialysis. Sep. Sci. Technol. 42:931-948. https://doi.org/10 .1080/01496390701206413.

González Siso, M. I. 1996. The biotechnological utilization of cheese whey: A review. Bioresour. Technol. 57:1-11. https://doi.org/10 .1016/0960-8524(96)00036-3.

Greiter, M., S. Novalin, M. Wendland, K. D. Kulbe, and J. Fischer. 2002. Desalination of whey by electrodialysis and ion exchange resins: Analysis of both processes with regard to sustainability by calculating their cumulative energy demand. J. Membr. Sci. 210:91-102. https://doi.org/10.1016/S0376-7388(02)00378-2. 
Hoppe, G. K., and J. J. Higgins. 1992. Demineralization. Pages 91-131 in Whey and Lactose Processing. J. G. Zadow, ed. Springer, Dordrecht, Germany. https://doi.org/10.1007/978-94-011-2894-0_3.

Houldsworth, D. W. 1979. Whey technology. Demineralization of whey by means of ion exchange and electrodialysis. J. Soc. Dairy Technol. 33:45-51. https://doi.org/10.1111/j.1471-0307.1980.tb01470 .x.

ISO. (International Organization for Standardization). 2002. method ISO 14891:2002 (IDF 185:2002) Milk and milk products-Determination of nitrogen content-Routine method using combustion according to the Dumas principle. International Organization for Standardization, Geneva, Switzerland.

Krol, J. J., M. Wessling, and H. Strathmann. 1999. Concentration polarization with monopolar ion exchange membranes: Currentvoltage curves and water dissociation. J. Membr. Sci. 162:145-154 https://doi.org/10.1016/S0376-7388(99)00133-7.

Lebrun, L., E. Da Silva, G. Pourcelly, and M. Métayer. 2003. Elaboration and characterisation of ion-exchange films used in the fabrication of bipolar membranes. J. Membr. Sci. 227:95-111. https://doi .org/10.1016/J.MEMSCI.2003.07.022.

Lorrain, Y., G. Pourcelly, and C. Gavach. 1996. Influence of cations on the proton leakage through anion-exchange membranes. J. Membr Sci. 110:181-190. https://doi.org/10.1016/0376-7388(95)00246-4.

Lteif, R., L. Dammak, C. Larchet, and B. Auclair. 1999. Conductivité électriquemembranaire: étude de l'effet de la concentration, de la nature de l'électrolyte et de la structure membranaire. Eur. Polym. J. 35:1187-1195. https://doi.org/10.1016/S0014-3057(98)00213-4.

Mikhaylin, S., and L. Bazinet. 2016. Fouling on ion-exchange membranes: Classification, characterization and strategies of prevention and control. Adv. Colloid Interface Sci. 229:34-56. https://doi .org/10.1016/j.cis.2015.12.006.

Mikhaylin, S., V. Nikonenko, N. Pismenskaya, G. Pourcelly, S. Choi H. J. Kwon, J. Han, and L. Bazinet. 2016. How physico-chemical and surface properties of cation-exchange membrane affect membrane scaling and electroconvective vortices: Influence on performance of electrodialysis with pulsed electric field. Desalination 393:102-114. https://doi.org/10.1016/j.desal.2015.09.011.

Mikhaylin, S., V. Nikonenko, G. Pourcelly, and L. Bazinet. 2014 Intensification of demineralization process and decrease in scaling by application of pulsed electric field with short pulse/pause conditions. J. Membr. Sci. 468:389-399. https://doi.org/10.1016/j .memsci.2014.05.045.
Panesar, P. S., J. F. Kennedy, D. N. Gandhi, and K. Bunko. 2007. Bioutilisation of whey for lactic acid production. Food Chem. 105:1-14. https://doi.org/10.1016/j.foodchem.2007.03.035.

Ryan, M. P., and G. Walsh. 2016. The biotechnological potential of whey. Rev. Environ. Sci. Biotechnol. 15:479-498. https://doi.org/ 10.1007/s11157-016-9402-1.

Saffari, M., and T. Langrish. 2014. Effect of lactic acid in-process crystallization of lactose/protein powders during spray drying. J. Food Eng. 137:88-94. https://doi.org/10.1016/j.jfoodeng.2014.04.002.

Schultz, E. J., and R. Parekh. 2011. Strong consumer demand pushes Greek yogurt into a dairy-aisle battlefield. Advert. Age 82:8.

Serre, E., E. Rozoy, K. Pedneault, S. Lacour, and L. Bazinet. 2016. Deacidification of cranberry juice by electrodialysis: Impact of membrane types and configurations on acid migration and juice physicochemical characteristics. Separ. Purif. Tech. 163:228-237. https://doi.org/10.1016/j.seppur.2016.02.044.

Strathmann, H. 2010. Electrodialysis, a mature technology with a multitude of new applications. Desalination 264:268-288. https://doi .org/10.1016/j.desal.2010.04.069

Tsakali, E., K. Petrotos, and A. D. Allessandro. 2010. A review on whey composition and the methods used for its utilization for food and pharmaceutical products. 6th Int. Conf. Simul. Model. Food Biol. Industry. FOODSIM 8.

Williams, A. W., and H. A. Kline, inventors. 1980. Borden Inc., Columbus, $\mathrm{OH}$, assignee. Electrodialysis of acid whey. United States Pat. 6-7.

$\mathrm{Xu}, \mathrm{T} .2005$. Ion exchange membranes: State of their development and perspective. J. Membr. Sci. 263:1-29. https://doi.org/10.1016/j .memsci.2005.05.002.

Zabolotskii, V. I., V. V. Bugakov, M. V. Sharafan, and R. K. Chermit. 2012. Transfer of electrolyte ions and water dissociation in anion-exchange membranes under intense current conditions. Russ. J. Electrochem. 48:650-659. https://doi.org/10.1134/ S1023193512060158.

Zeppenfeld, K. 2011. Electrochemical removal of calcium and magnesium ions from aqueous solutions. Desalination 277:99-105. https://doi.org/10.1016/j.desal.2011.04.005.

Zhang, Y., and R. A. Dawe. 2000. Influence of Mg2+ on the kinetics of calcite precipitation and calcite crystal morphology. Chem. Geol 163:129-138. https://doi.org/10.1016/S0009-2541(99)00097-2. 